\title{
Morphological Physiological and Transcriptional Response to Low Nitrogen Stress in Populus Deltoides Marsh. Clones With Contrasting Nitrogen Use Efficiency
}

\section{Cun Chen}

State Key Laboratory of Tree Genetics and Breeding, Research Institute of Forestry, Chinese Academy of Forestry

\section{Yanguang Chu}

State Key Laboratory of Tree Genetics and Breeding, Research Institute of Forestry, Chinese Academy of Forestry

\section{Qinjun Huang}

State Key Laboratory of Tree Genetics and Breeding, Research Institute of Forestry, Chinese Academy of Forestry

\section{Weixi Zhang}

State Key Laboratory of Tree Genetics and Breeding, Research Institute of Forestry, Chinese Academy of Forestry

\section{Changjun Ding}

State Key Laboratory of Tree Genetics and Breeding, Research Institute of Forestry, Chinese Academy of

Forestry

\section{Jing Zhang}

State Key Laboratory of Tree Genetics and Breeding, Research Institute of Forestry, Chinese Academy of Forestry

Bo Li

State Key Laboratory of Tree Genetics and Breeding, Research Institute of Forestry, Chinese Academy of Forestry

\section{Tengqian Zhang}

State Key Laboratory of Tree Genetics and Breeding, Research Institute of Forestry, Chinese Academy of Forestry

\section{Zhenghong Li}

State Key Laboratory of Tree Genetics and Breeding, Research Institute of Forestry, Chinese Academy of Forestry

\section{Xiaohua Su ( $\nabla$ suxh@caf.ac.cn )}

State Key Laboratory of Tree Genetics and Breeding, Research Institute of Forestry, Chinese Academy of Forestry 


\section{Research Article}

Keywords: nitrogen deficiency, nitrogen use efficiency, gene expression, Populus deltoides Marsh

Posted Date: January 23rd, 2021

DOl: https://doi.org/10.21203/rs.3.rs-149379/v1

License: (c) (i) This work is licensed under a Creative Commons Attribution 4.0 International License. Read Full License 
1 Morphological physiological and transcriptional response to low

2 nitrogen stress in Populus deltoides Marsh. clones with contrasting

3 nitrogen use efficiency

4

5

6

7

8

Cun Chen ${ }^{1,2+}$, Yanguang Chu ${ }^{1,2+}$, Qinjun Huang ${ }^{1,2}$, Weixi Zhang ${ }^{1,2}$, Changjun Ding ${ }^{1,2}$, Jing Zhang $^{1,2}$, Bo Li ${ }^{1,2}$, Tengqian Zhang ${ }^{1,2}$, Zhenghong $\mathrm{Li}^{1,2}$, Xiaohua $\mathrm{Su}^{1,2,3,{ }^{*}}$

${ }^{1}$ State Key Laboratory of Tree Genetics and Breeding, Research Institute of Forestry, Chinese Academy of Forestry.

${ }^{2}$ Key Laboratory of Tree Breeding and Cultivation, State Forestry and Grassland Administration, Beijing, China.

${ }^{3}$ Co-Innovation Center for Sustainable Forestry in Southern China, Nanjing Forestry University, Nanjing, Jiangsu Province, China.

† These authors contributed equally to this work.

* Correspondence: suxh@caf.ac.cn; Tel.: 86-10-6288-9627

Email addresses:

CC: chencun0610@163.com; YGC: ygchu@126.com; QJH: huangqi@caf.ac.cn; WXZ: weixizhang@126.com; CJD: changjund@126.com; JZ: zjshs1@163.com; BL: libo1996312@163.com; TQZ: tengqianzhang66@126.com; ZHL: iamgintman@163.com; XHS: $\underline{\operatorname{suxh} @ \text {,caf.ac.cn }}$ 


\section{Abstract:}

Background: Nitrogen $(\mathrm{N})$ is one of the main factors limiting the wood yield in poplar cultivation.

Understanding the molecular mechanism of $\mathrm{N}$ utilization could play a guiding role in improving the nitrogen use efficiency (NUE).

Results: In this study, three N-efficient genotypes (A) and three N-inefficient genotypes (C) of Populus deltoides were cultured under low $\mathrm{N}$ stress $\left(5 \mu \mathrm{M} \mathrm{NH}_{4} \mathrm{NO}_{3}\right)$ and normal $\mathrm{N}$ supply $(750 \mu \mathrm{M}$ $\mathrm{NH}_{4} \mathrm{NO}_{3}$ ). The dry matter mass, leaf morphology, and chlorophyll content of both genotypes decreased under $\mathrm{N}$ starvation. Interestingly, $\mathrm{N}$ starvation induced fine root growth in $\mathrm{A}$, but not in C. Next, a detailed time-course analysis of enzyme activities and gene expression in leaves identified 2,062 differentially expressed genes (DEGs) in A and 1,118 in C, most of which were up-regulated. Moreover, the sensitivity to $\mathrm{N}$ starvation of $\mathrm{A}$ was weak, and DEGs related to hormone signal transduction played an important role in the low $\mathrm{N}$ response in $\mathrm{A}$. The weighted gene co-expression network analysis identified genes related to membrane, catalytic activity, enzymatic activity, and response to stresses might be critical for poplar's adaption to $\mathrm{N}$ starvation and these genes participated in the negative regulation of various biological processes. Finally, ten influential hub genes and twelve transcription factors were identified in the response to $\mathrm{N}$ starvation, among them Podel.19G001200, Podel.19G035300, Podel.02G021400, and Podel.04G076900 were related to programmed cell death, and the defense response, and PodelWRKY41, PodelWRKY75, PodelWRKY18, PodelBHLH25, PodelBHLH30, PodelBHLH, and PodelHY5 were involved in plant signal transduction.

Conclusions: Under the condition of $\mathrm{N}$ starvation, A showed stronger adaptability and a better NUE than $\mathrm{C}$ in morphology and physiology. The discovery of hub genes and TFs provided a new 
information for the analysis of the molecular mechanism of $\mathrm{N}$ efficient utilization and the improvement of NUE of poplar.

Keywords: nitrogen deficiency; nitrogen use efficiency; gene expression; Populus deltoides Marsh.

\section{Background}

Nitrogen $(\mathrm{N})$ is an essential macronutrient for plant growth and development, and is not only an important constituent of nucleic acids, proteins, hormones, and chlorophyll, but also participates in a variety of biological processes as a signal to regulate the growth of aboveground and underground parts of plants [1-3]. Meanwhile, $\mathrm{N}$ is the main limiting factor of plant productivity and crop yield [4]. Therefore, the application of $\mathrm{N}$ fertilizer in agricultural production has become the main method to improve crop yield; however, in practice, only about 30 to $40 \%$ of the applied $\mathrm{N}$ fertilizer is absorbed by crops and used effectively; the rest is retained in the soil or integrated into water resources, which not only wastes resources but also affects the nutrient balance, resulting in environmental pollution [1, 5-7]. Moreover, it is not feasible to increase the timber yield of perennial trees by fertilization; therefore, it is particularly important to improve the nitrogen use efficiency (NUE) of plants for crops, especially for trees.

NUE is a comprehensive characteristic of the interaction between available $\mathrm{N}$ content in the plant growth environment and various biological processes, including absorption, transport, assimilation, signal transduction, and regulation [8]. In general, NUE mainly includes two aspects: $\mathrm{N}$ uptake efficiency (NUpE) and $\mathrm{N}$ utilization efficiency (NUtE). $\mathrm{NUpE}$ is mainly used to measure the level of $\mathrm{N}$ uptake through $\mathrm{N}$ transporters in plant roots, which is closely related to the architecture 
and growth status of the roots. NUtE mainly reflects the ability of plants to transport, assimilate, and utilize $\mathrm{N}$, which is related to enzyme activities in plants and the photosynthetic capacity of the leaves [9]. N-efficient plants should have a high NUpE and a high NUtE [10]. The absorption of N is the first step in the utilization of $\mathrm{N}$, and the ability of NUpE directly determines the NUE of plants [11-12]. Plants usually acquire $\mathrm{N}$ from the soil in the form of $\mathrm{NO}_{3}{ }^{-}$and $\mathrm{NH}_{4}{ }^{+}$by the roots, with the help of specific transporters, including nitrate transporters (NRTs) and ammonium transporters (AMTs) [13]. Recent studies on NUE have mainly focused on the root system, and many key genes related to $\mathrm{N}$ transport have been discovered in roots [14-15]. We believe that there is a close relationship between roots and leaves in the form of a 'source-sink'. In addition, gene expression and physiological activity in the leaves, especially photosynthesis, play an important role in NUtE [16]. In previous studies, key genes involved in the response to low $\mathrm{N}$ stress in leaves were ignored. Studying the mechanism of NUE, and selecting N-efficient genotypes are effective strategies to achieve a stabilized yield and high NUE. However, because of the promotion of single cultivation in crop and forest production, the genetic diversity of NUE has become narrower, representing a bottleneck for the genetic improvement of NUE [17]. The most plausible approach is to excavate favorable natural genetic variation from existing germplasm resources under low $\mathrm{N}$ stress, to study the molecular genetic basis of favorable variation, and make full use of natural variation, thus laying a foundation for the selection of N-efficient genotypes and the improvement of NUE-related traits $[8,18]$.

In previous studies, we found that high-throughput transcriptome sequencing (RNA-seq) technology could effectively identify differentially expressed genes (DEGs) under low N stress, and was useful to mine key regulatory genes closely related to NUE [19-21]. Most of the studies focused 
on single genotypes under different $\mathrm{N}$ treatments [22-24]. In some crops, two genotypes with different NUEs were selected to explore the key genes involved in the regulation of $\mathrm{N}$ efficient utilization [10,25-26]. Meanwhile, there has been little analysis on the timeliness of plants' response to low $\mathrm{N}$ stress, especially perennial trees such as poplar.

The construction and analysis of gene-to-gene regulatory networks are useful to discover the potential key regulators among DEGs, and this method has been applied in many studies to identify key regulatory genes in the network [22, 27-29]. In multi-sample $(\geq 15)$ RNA-seq data analysis, combined with the phenotypic or physiological characteristics data, weighted gene co-expression network analysis (WGCNA) could realize the high clustering of a large number of DEGs, and select the gene modules that are closely related to specific traits, from which the hub genes can be screened quickly and effectively by constructing expression regulation networks according to the connectivity of genes and the weight of gene correlation in the special module. WGCNA has been widely used for key gene mining in response to biotic and abiotic stresses [26, 30-31].

Populus species are fast-growing and easily propagated woody plants, which play an important role in ecological protection and wood production. Poplar is one of the main afforestation tree species in the middle latitude of the world. However, with the gradual expansion of the poplar plantation area, they often grow in poor lands where soil $\mathrm{N}$ is limited [32-33]. Therefore, it is necessary to explore the mechanism of poplar's $\mathrm{N}$ efficient utilization and improve its NUE. Populus deltoides Marsh. (P. deltoides), with high genetic diversity, is often used in research into poplar hybrid breeding as a parent [34]. In our previous study, 338 genotypes of $P$. deltoides were classified according to their NUE, and $26 \mathrm{~N}$-efficient genotypes and $24 \mathrm{~N}$-inefficient genotypes were obtained [35]. In the present study, three genotypes were selected from two contrasting groups, respectively, 
111

112

and were treated with low $\mathrm{N}$ stress for 40 days. The morphological and physiological differences between the genotypes were analyzed. Meanwhile, a detailed time-course analysis of enzyme activities and gene expression related to $\mathrm{N}$ metabolism in leaves was carried out, and the key genes or transcription factors (TFs) responding to low $\mathrm{N}$ stress were mined using WGCNA, which would provide a valuable resource to further develop strategies to improve the NUE in poplar.

\section{Results}

\section{Differences in Growth Characteristics under Low N stress}

Compared with normal $\mathrm{N}$ supply (CK) treatment, the average plant height (Hn) of the N-efficient and $\mathrm{N}$-inefficient genotypes decreased by $8.56 \%$ and $10.39 \%$ under low nitrogen (LN) treatment after 40 days, respectively, and the average ground diameter (GDn) decreased by $2.90 \%$ and $5.94 \%$, respectively (Fig. 1A, B). Similarly, under LN treatment, the average fresh weight of the stem (SFW) and dry weight of the stem (SDW) of N-efficient plants decreased by $12.89 \%$ and $15.74 \%$, respectively, while the SFW and SDW of the N-inefficient plants decreased by $15.22 \%$ and $23.89 \%$, respectively (Fig. 1C, D). Notably, the fresh weight of the root (RFW) of the N-efficient genotypes increased slightly $(0.91 \%)$, while the RFW of the $\mathrm{N}$-inefficient genotypes decreased significantly $(15.00 \% ; p<0.05)$. By contrast, the dry weight of the root (RDW) of the N-efficient and Ninefficient genotypes (except the C-1 clone) was significantly reduced $(p<0.05)$ under $\mathrm{LN}$ treatment (Fig. 1E, F). Moreover, the fresh weight (LFW) and dry weight (LDW) of a single leaf of the Nefficient and N-inefficient genotypes decreased under LN treatment, and the values of LFW and LDW of the $\mathrm{N}$-efficient genotypes were higher than those of the $\mathrm{N}$-inefficient genotypes under CK or LN treatment (Fig. 1G, H). As shown in Table S7, the low N adaptation coefficient (LNAC) of 

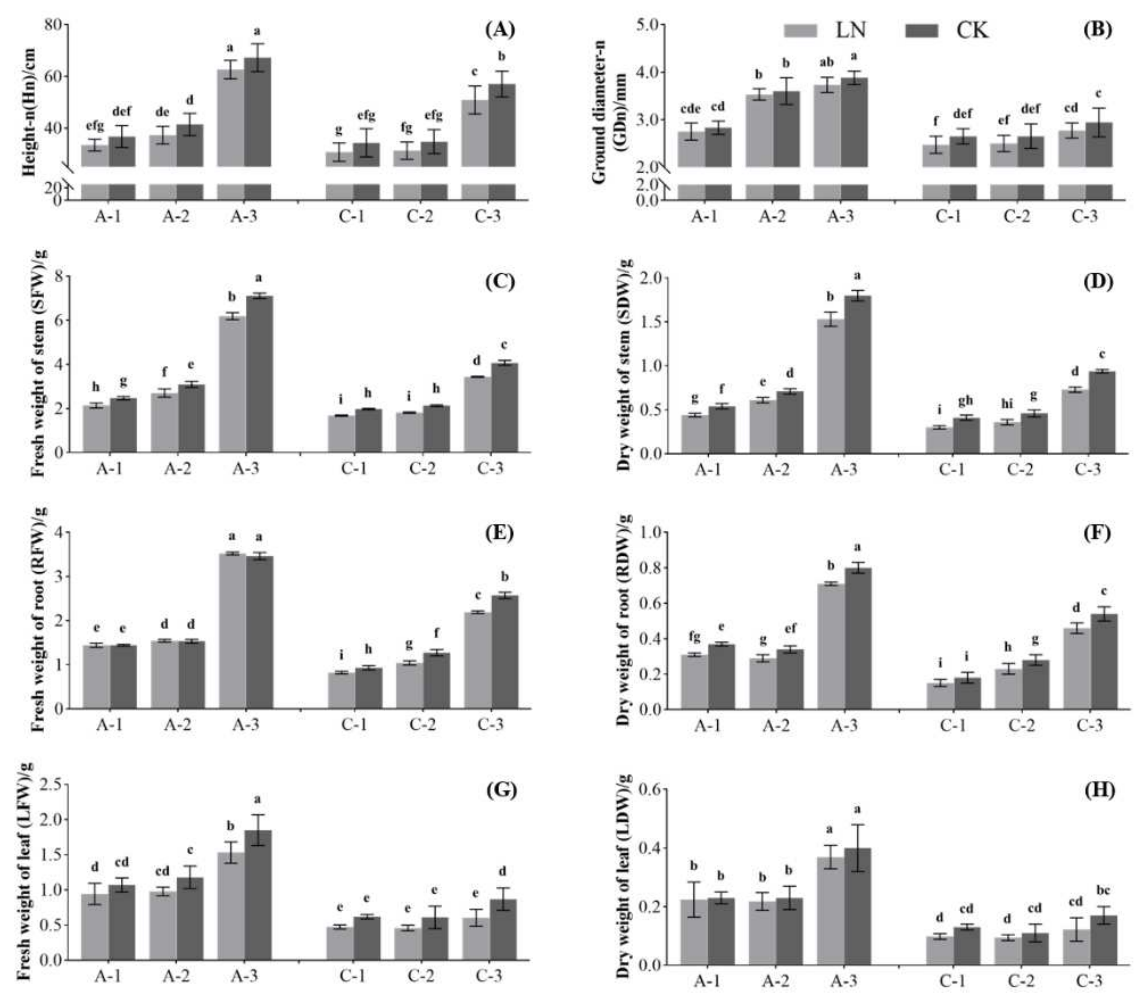

Fig. 1. Effects of low $N$ stress on growth traits of $N$-efficient (A-1, A-2, and A-3) and N-inefficient (C-1, C-2, and C-3) genotypes. Different letters above the column indicate significant differences between groups $(p<0.05)$. (A) Height after treatment (Height-n, Hn); (B) Ground diameter after treatment (Ground diameter-n, GDn); (C) Fresh weight of the stem (SFW); (D) Dry weight of the stem (SDW); (E) Fresh weight of the root (RFW); (F) Dry weight of the root (RDW); (G) Fresh weight of the leaf (LFW); (H) Dry weight of the leaf (LDW).

\section{Differences in Leaf Morphology and Chlorophyll Content under Low N Stress}

After $\mathrm{N}$ treatment, the contents of chlorophyll a (Chl a), chlorophyll b (Chl b), carotenoids (Car), and total chlorophyll (Chl) of plants (N-efficient and N-inefficient genotypes) under LN treatment were significantly lower than those under CK treatment (Fig. 2A, B, C, D; $p<0.05$ ). Besides, the chlorophyll contents (Chl a, Chl b, Car, and Chl) of the N-efficient genotypes were higher than those of the N-inefficient genotypes under LN or CK treatment (Fig. 2A, B, C, D). Compared with CK treatment, leaf morphological traits [leaf length (LL), leaf width (LW), and leaf area (LA)] were 
reduced under $\mathrm{LN}$ treatment. The LL, LW, and LA of the N-efficient genotypes decreased by 9.43 ,

151

8.99 , and $15.50 \%$, respectively, while those of the $\mathrm{N}$-inefficient genotypes decreased by $15.22,14.64$, and $30.58 \%$, respectively. In particular, the LA of the N-efficient genotypes was significantly higher than that of the N-inefficient genotypes (Fig. 2E, F, G; $p<0.05$ ). The average LNAC values of Chl a, Chl b, Car, Chl, LL, LW, and LA of the N-efficient genotypes were higher than those of the Ninefficient genotypes, but the differences were not significant (Table S1).
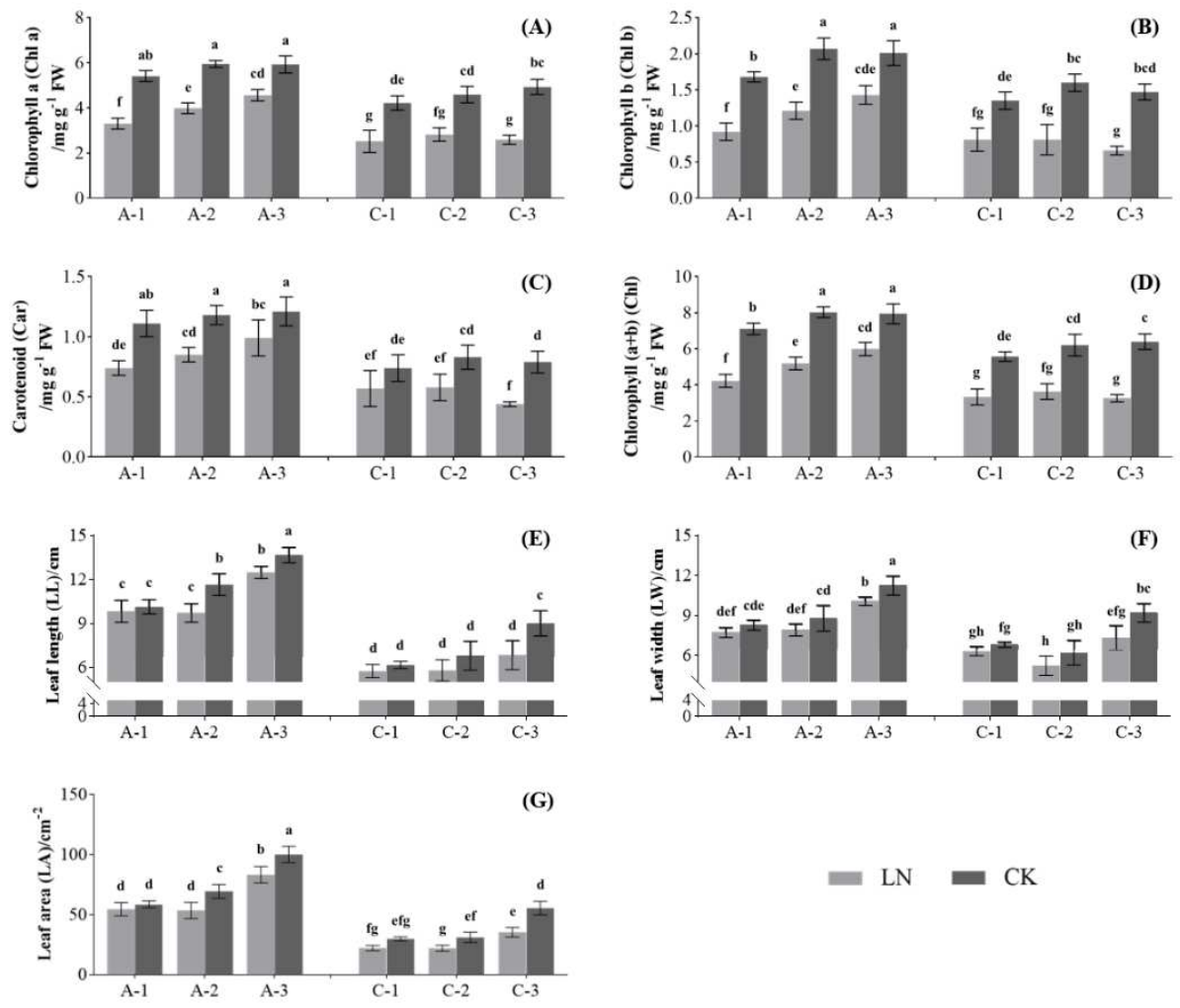

$=\mathrm{LN}=\mathrm{CK}$

Fig. 2. Effects of low $\mathrm{N}$ stress on leaf morphology and chlorophyll content of N-efficient (A-1, A2 and A-3) and N-inefficient (C-1, C-2 and C-3) genotypes. Different letters above the column indicate significant differences between the groups $(p<0.05)$. (A) Chlorophyll a (Chl a); (B) Chlorophyll b (Chl b); (C) Carotenoid (Car); (D) Chlorophyll (a+b) (Chl); (E) Leaf length (LL); (F) Leaf width (LW); (G) Leaf area (LA).

\section{Differences in the Response of Enzyme Activities under Low N Stress}

To study the differences between the two contrasting genotypes in response to low $\mathrm{N}$ stress, we measured the enzyme activities (NR, GS, GDH, and GOGAT), total amino acid contents (AAs), and 
soluble sugar contents (SSs) of mixed leaf samples at seven time points. As shown in Fig. 3, the enzyme activities in leaves of the N-efficient (A) and N-inefficient (C) genotypes were inhibited under LN treatment. The AAs and SSs were decreased. Under LN treatment, the NR activities of genotypes $\mathrm{A}$ and $\mathrm{C}$ were different, and the activity reached the lowest at T4 (Fig. 3A). With the increase in LN treatment time, the activities of GS and GOGAT of genotypes A and C increased first and then decreased, with the turning point of change mostly occurring at $\mathrm{T} 2$ (except for the change of GS activity of A, Fig. 3B, D). Besides, the GDH activity of A decreased first and then increased, while that of $\mathrm{C}$ decreased continuously (Fig. 3C). The AAs of genotypes A and C decreased continuously in response to low $\mathrm{N}$ stress (Fig. 3E). In particular, at the beginning of low $\mathrm{N}$ stress, the SSs of A decreased and then increased gradually, while genotype C showed the opposite response

\section{(Fig. 3F).}
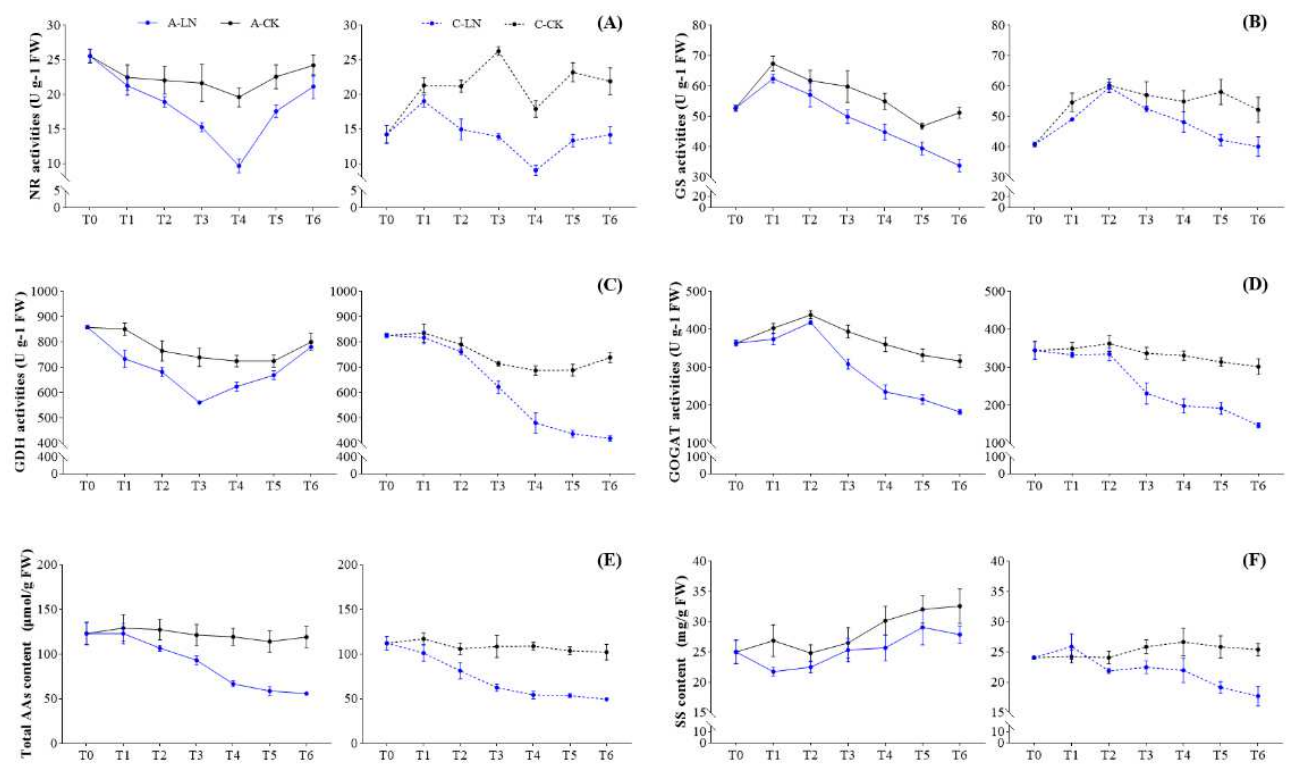

Fig. 3. The change trends of enzyme activities, total amino acid contents, and soluble sugar contents in leaves during $\mathrm{N}$ treatment of $\mathrm{N}$-efficient (A) and $\mathrm{N}$-inefficient (C) genotypes. T0, T1, T2, T3, T4, $\mathrm{T} 5$, and $\mathrm{T} 6$ represent $0,3,5,10,20,30$, and 40 days of $\mathrm{N}$ treatment, respectively. (A) Nitrate reductase activities (NR); (B) Glutamine synthetase activities (GS); (C) Glutamate dehydrogenase activities (GDH); (D) Glutamic acid synthetase activities (GOGAT); (E) Total amino acid contents (AAs); (F) Soluble sugar contents (SSs). 
185

186

187

\section{Evaluation of RNA Sequencing Data}

According to the change trends of enzyme activities, AAs and SSs in the process of LN treatment, the mixed leaf samples of N-efficient (A) and N-inefficient (C) genotypes at 0 (T0), 5 (T2), 20 (T4), and 40 (T6) days after LN treatment, with three biological replicates (T0-A-1, T0-A-2, T0-A-3, T0C-1, T0-C-2, T0-C-3, T2-LN-A-1, T2-LN-A-2, T2-LN-A-3, T2-LN-C-1, T2-LN-C-2, T2-LN-C-3, T4-LN-A-1, T4-LN-A-2, T4-LN-A-3, T4-LN-C-1, T4-LN-C-2, T4-LN-C-3, T6-LN-A-1, T6-LNA-2, T6-LN-A-3, T6-LN-C-1, T6-LN-C-2, and T6-LN-C-3,) were selected for transcriptome sequencing analysis. A total of $36,866,796-61,136,254$ clean reads were generated, of which approximately $76.89-87.63 \%$ were uniquely mapped to the genome of $P$. deltoides (Table S2). The Pearson correlation coefficient between the biological replicates ranged from 0.9810 to 0.9977 (Fig. S1), implying that the RNA-seq data were highly reliable.

\section{DEGs between $N$-efficient and $N$-inefficient genotypes under Low $N$ Stress}

To study the differences of response to low $\mathrm{N}$ stress of the two genotypes (A and C), we detected the DEGs between A and C comparison groups at four-time points (T0-C vs. T0-A, T2-LN-C vs. T2-LN-A, T4-LN-C vs. T4-LN-A, and T6-LN-C vs. T6-LN-A), and 2,383; 1,243; 1,292; and 3,055

DEGs were detected, respectively. Compared with genotype C, 1,149 DEGs were upregulated and 1,906 genes were downregulated in genotype A at T6 (Fig. 4A). As shown in the Venn diagram (Fig. 4B), there were 397 common DEGs in T0, T2, T4, and T6 between the genotypes A and C, and 972, 225, 224, and 1,578 specific DEGs at T0, T2, T4, and T6, respectively. 

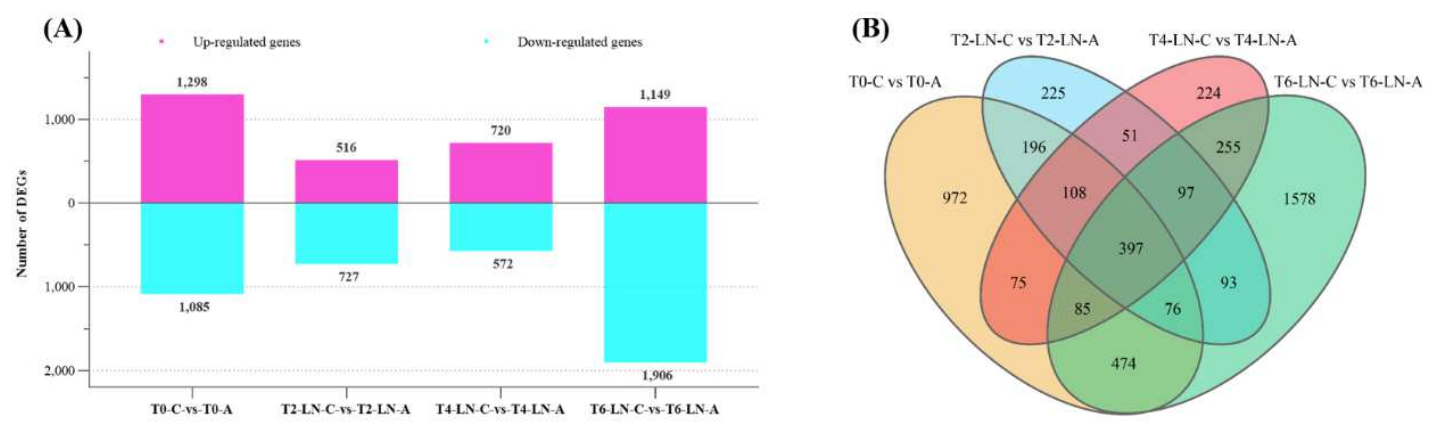

Fig. 4. (A) Bar chart showing numbers of upregulated and downregulated differentially expressed genes (DEGs) in the four comparison groups (T0-C vs. T0-A, T2-LN-C vs. T2-LN-A, T4-LN-C vs. T4-LN-A and T6-LN-C vs. T6-LN-A). The magenta column shows upregulated DEGs, and the cyan column shows downregulated DEGs. LN: low nitrogen treatment. (B) Venn diagram showing that the distribution of DEGs identified in the comparison of genotypes $\mathrm{A}$ and $\mathrm{C}$ are common and specific to $\mathrm{T} 0, \mathrm{~T} 2, \mathrm{~T} 4$, and $\mathrm{T} 6$.

The Kyoto Encyclopedia of Genes and Genomes (KEGG) pathway enrichment analysis of specific and common genes at different time points between genotypes $\mathrm{A}$ and $\mathrm{C}$ showed that the specific DEGs at T0 were mainly enriched in the biosynthesis of secondary metabolites, glutathione metabolism, starch and sucrose metabolism, phenylalanine metabolism, flavonoid biosynthesis, and thiamine metabolism (Fig. 5). The 225 specific DEGs at T2 were specifically enriched for ascorbate and aldarate metabolism, and one environmental information processing category ( $\mathrm{ABC}$ transporters). The specific DEGs at T6 were specifically enriched for metabolism (metabolic pathways, phenylpropanoid biosynthesis, tyrosine metabolism, fatty acid metabolism, pentose and glucuronate interconversions, and indole alkaloid biosynthesis) and plant hormone signal transduction. The common DEGs were mainly enriched in photosynthesis, oxidative phosphorylation, DNA replication, and homologous recombination pathways. These results suggest that genotypes $\mathrm{A}$ and $\mathrm{C}$ have different response mechanisms to low $\mathrm{N}$ stress. 

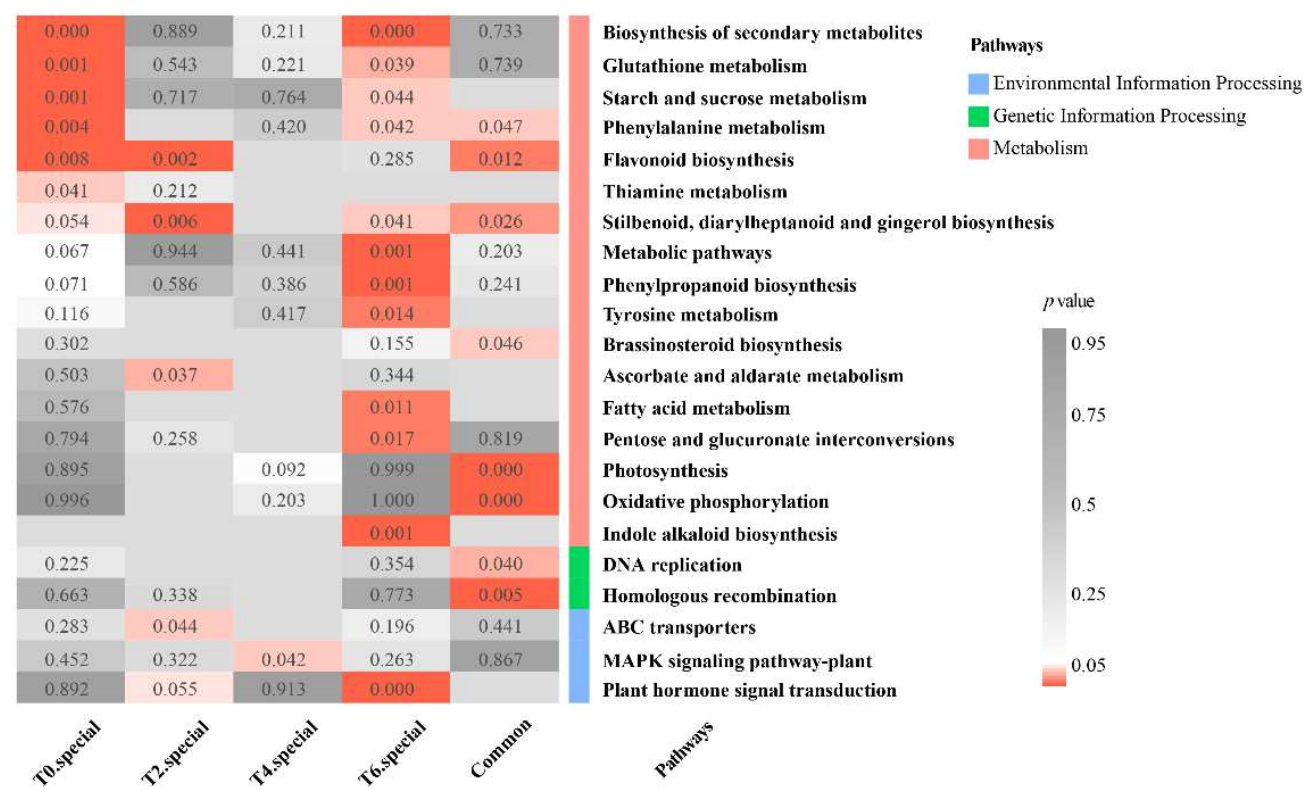

Fig. 5. Results of the Kyoto Encyclopedia of Genes and Genomes (KEGG) pathway enrichment analysis of the special and common differentially expressed genes (DEGs) between genotypes A and $\mathrm{C}$ at different time points during the response to low $\mathrm{N}$ stress. T0 special, $\mathrm{T} 2$ special, $\mathrm{T} 4$ special, and T6 special represent the specific DEGs at T0, T2, T4, and T6 between genotypes A and C, respectively. Common indicates the common DEGs at T0, T2, T4, and T6 between genotypes A and $\mathrm{C}$.

\section{DEGs during Low $N$ Stress of $N$-efficient and $N$-inefficient genotypes}

The DEGs of genotypes A and $\mathrm{C}$ at different time points under low $\mathrm{N}$ stress were determined to

study the differences of response mechanisms of two genotypes. Three different comparison groups

of genotype A at the early stage (T0-A vs. T2-LN-A), the middle stage (T2-LN-A vs. T4-LN-A), and the late stage (T4-LN-A vs. T6-LN-A) were constructed, and 445 (272 upregulated and 173 downregulated), 2,337 (1,624 upregulated and 713 downregulated), and 692 (219 upregulated and 473 downregulated) DEGs were detected, respectively (Fig. 6A). Three corresponding comparison groups of genotype C (early stage: T0-C vs. T2-LN-C, middle stage: T2-LN-C vs. T4-LN-C. and late-stage: T4-LN-C vs. T6-LN-C) were constructed, and 1,635 (1,231 upregulated and 404 downregulated), 598 (153 upregulated and 445 downregulated) and 226 (132 upregulated and 94 downregulated) DEGs were identified, respectively (Fig. 6B). The results showed that the gene 


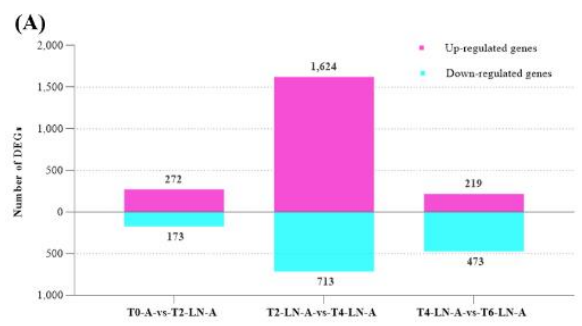

(C)
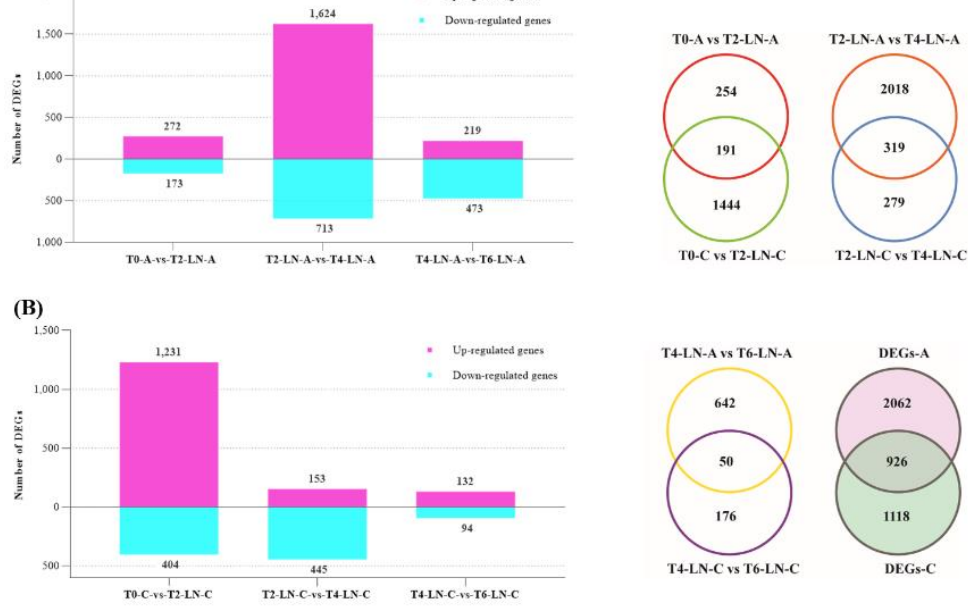


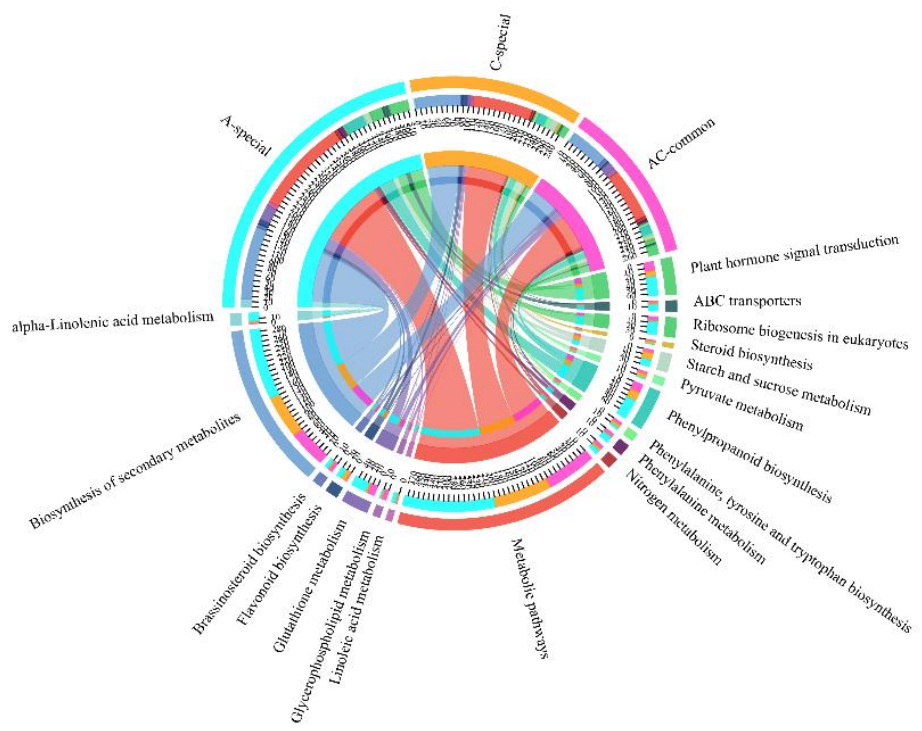

Fig. 7. Results of the Kyoto Encyclopedia of Genes and Genomes (KEGG) pathway enrichment analysis of the special and common differentially expressed genes (DEGs) between genotypes A and $\mathrm{C}$ during the response to low $\mathrm{N}$ stress. A-special and $\mathrm{C}$-special represent the specific DEGs in genotypes $\mathrm{A}$ and $\mathrm{C}$, respectively. AC-common indicates the common DEGs between genotypes $\mathrm{A}$ and $\mathrm{C}$.

\section{Trend Analysis of DEGs}

For genotypes A and C, DEGs that were detected in response to low N stress at four-time points were clustered into 20 profiles, among which 2,988 DEGs of genotype A were significantly enriched in six profiles (profile $0,6,9,10,12$, and 13), and profile 12 contained the largest number of genes $(1,168)$, which was similar to the previous research results, i.e., the genes in genotype A mainly responded in the middle stage of low $\mathrm{N}$ stress, and less in the early and late stages (Fig. 8A, B). For genotype C, 2,044 DEGs were significantly enriched in four profiles (profile 2, 14, 15, and 17), among which profile 17 contained the largest number of genes (629), which showed that genes mainly responded at the early stage of treatment, and fewer genes participated in the middle and late stages (Fig. 8C, D). 
(A)

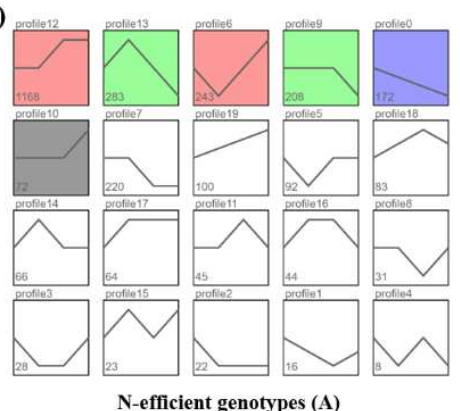

(C)

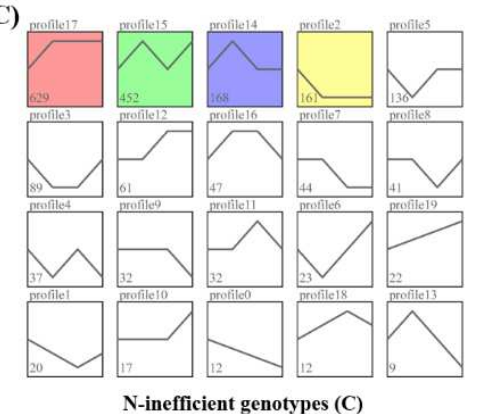

(B)

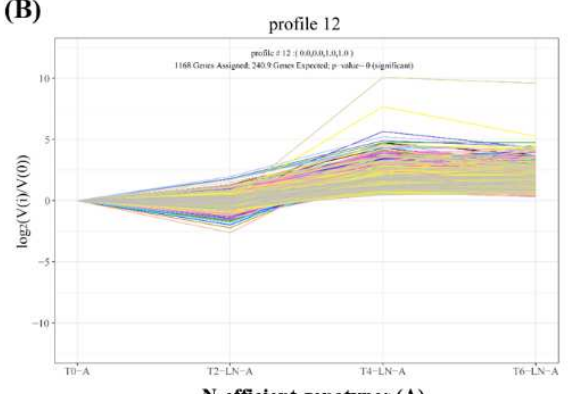

N-efficient genotypes (A)

(D)

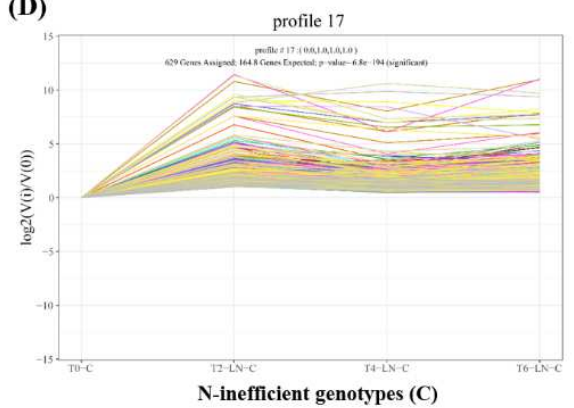

Fig. 8. Gene expression patterns across four-time points (T0, T2, T4, and T6) in genotypes A and C under low $\mathrm{N}$ stress. (A) and (C) indicate the variation trend of differentially expressed genes (DEGs) in genotypes $\mathrm{A}$ and $\mathrm{C}$, respectively. Above the box is the ID of the changing trend, and the number in the box indicates the number of DEGs contained in the trend. The grid with color indicates a significantly enrichment trend $(p<0.05)$, and the closer the color is, the more similar the changing trend is. (B) and (D) represent the changing trend of genes in profile 12 with genotype A and profile 17 with genotype $\mathrm{C}$, respectively.

Many genes in profile 12 of genotype A (A-profile 12) and profile 17 of genotype C (C-profile

17) were enriched in the pathway of biosynthesis of secondary metabolites. Most of the pathways of gene enrichment in A-profile 12 were related to the biological processes of $\mathrm{N}$ absorption, transformation, transport, and assimilation (glutathione metabolism, phenylalanine metabolism, cysteine, and methionine metabolism, biosynthesis of amino acids, and $\mathrm{ABC}$ transporters), while the genes in C-profile 17 were significantly enriched in brassinosteroid biosynthesis, amino sugar, and nucleotide sugar metabolism, fatty acid elongation, and $\mathrm{N}$ metabolism (Fig. 9). 


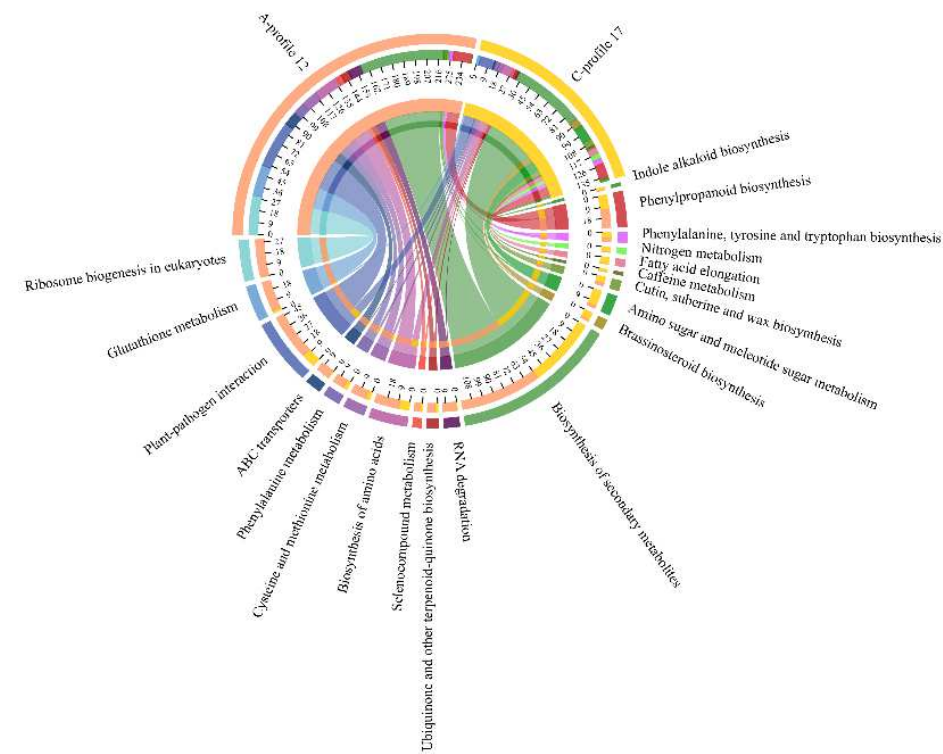

Fig. 9. Results of the Kyoto Encyclopedia of Genes and Genomes (KEGG) pathway enrichment analysis of differentially expressed genes (DEGs) in profile 12 of genotype A (A-profile 12) and profile 17 of genotype $C$ (C-profile 17 ). The 10 pathways on the left are the top-10 metabolic pathways with significantly enrichment in A-profile 12, and the 10 pathways on the right are the top-10 metabolic pathways with significantly enrichment in C-profile $17(p<0.05)$.

\section{Identification of WGCNA Modules Associated with Special Traits}

A total of 24 leaf samples of genotypes A and $\mathrm{C}$ at four-time points (three biological repeats) during low $\mathrm{N}$ treatment were used to carry out WGCNA. Based on the results (Fig. 10A), 4,106 genes were divided into 19 modules. Except for the grey module with only one gene, the other module sizes ranged from 59 ('royal blue') to 539 ('brown'). Through the correlation analysis between modules and experimental traits (NR, GS, GDH, GOGAT, AAs and SSs; Fig. 10B), it was found that the correlation coefficients between GS and 'magenta', 'blue', 'light green', and 'tan' were $-0.79,-0.81$, -0.78 , and 0.77 , respectively. Moreover, the 'magenta' module was not only significantly related to GS, but also correlated highly with GOGAT and AAs $(|\mathrm{r}|>0.75, p<0.05)$. Therefore, we speculated that genes in the 'magenta' module might play a key role in the plant response to low N stress. 

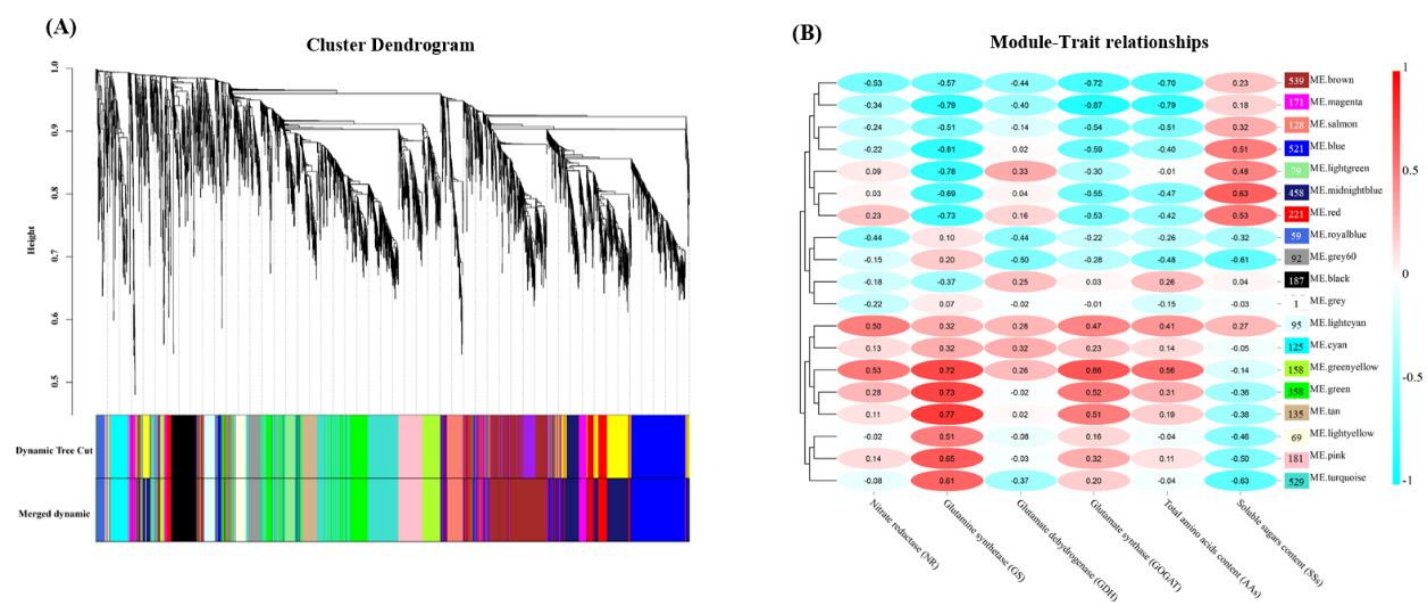

Fig. 10. Weighted gene co-expression network analysis (WGCNA) of differentially expressed genes (DEGs) identified in the genotypes $\mathrm{A}$ and $\mathrm{C}$ over three-time stages under low N stress. (A) Gene cluster dendrogram and 19 gene module divisions of DEGs, in which a major tree branch represents a module, and different colors represent different modules. (B) Correlation heatmap between modules and traits. Each column presents the experimental traits. The number in the oval box represents the correlation coefficient, which ranges from -1 (cyan) to 1 (red). We set an absolute value of the correlation coefficient greater than 0.75 to indicate that there is a strong correlation between gene modules and traits. The number in the rectangular box on the right indicates the number of the genes contained in the corresponding gene module.

\section{Gene Expression Trends and Function Analysis of a Specific Module}

The expression trends of genes in the 'magenta' module were similar in genotypes $\mathrm{A}$ and $\mathrm{C}$, and most of the genes had low expression at T0, after which expression increased gradually with the increase of the treatment time of low N stress; however, the expression trends of a few other genes were the opposite. Moreover, the expression of these genes in genotype A was more obvious than that in genotype C (Fig. S2). An analysis of functional annotations (Gene Ontology terms) revealed that genes in the 'magenta' module related to the membrane (GO:0016020), catalytic activity (GO:0003824), enzymatic activity [protein kinase activity (GO:0004672), phosphotransferase activity (GO:0016773), kinase activity (GO:0016301), transferase activity(GO:0016772)], response to stress (GO:0006950), and negative regulation of various biological processes [negative regulation of peptidase activity (GO:0010466), negative regulation of proteolysis (GO:0045861), negative regulation of catalytic activity (GO:0043086), negative regulation of molecular function 
(GO:0044092), negative regulation of cellular protein metabolic process (GO:0032269), and negative regulation of protein metabolic process (GO:0051248)]. The enriched GO terms are listed in Fig. 11 and Table S3.
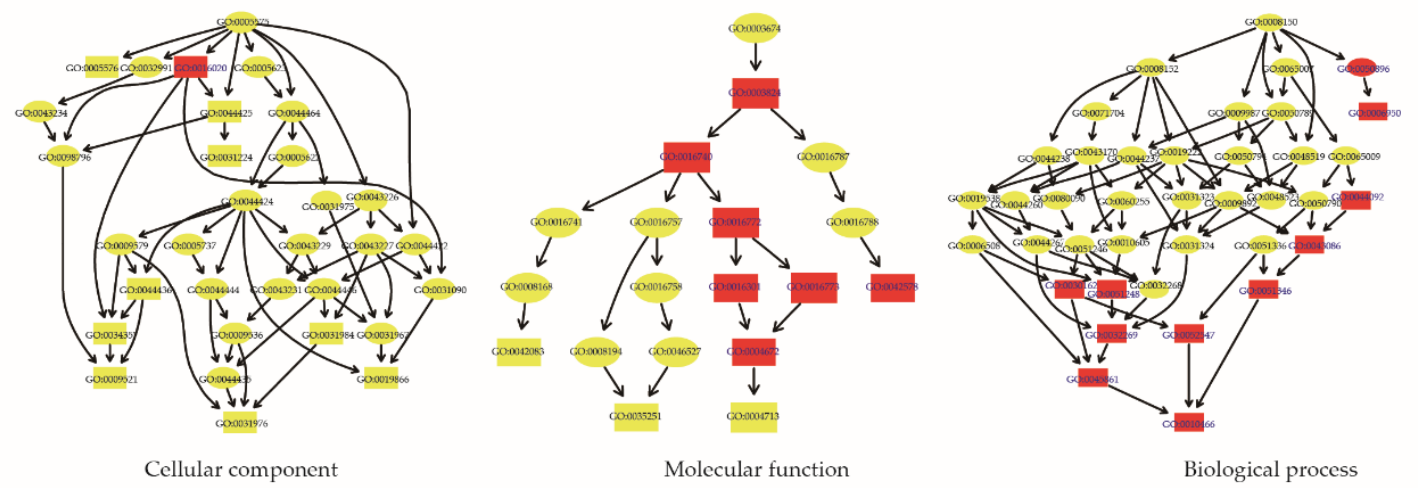

Fig. 11. Results of the gene ontology (GO) functional enrichment analysis of genes in the 'magenta' module. Red filled GO items were significantly enriched $(p<0.05)$ and yellow ones were not significantly enriched $(p>0.05)$. The rectangles in each network diagram represent the top $10 \mathrm{GO}$ terms with significance in cellular component, molecular function, and biological process, respectively.

\section{Co-expression Network Construction and Key Gene Mining in Specific Modules}

Based on the correlation of 171 genes in the 'magenta' module (Table S4), the top 10 genes in terms of connectivity (within the module) were selected as hub genes, and the gene pairs related to hub genes with the top 150 weight values were selected to construct the network graph (Fig. 12). The 10 genes (except one TF gene, Podel.18G019200) in the center of the network were hub genes, including genes encoding domain-containing proteins [DUF668 domain-containing protein/DUF3475 domain-containing protein (Podel.02G021400), MACPF domain-containing protein At4g24290-like (Podel.19G001200), ACT domain-containing protein ACR4 isoform X1 (Podel.08G129500), and C2 and GRAM domain-containing protein At1g03370-like (Podel.06G003100)], echinoderm microtubule-associated protein-like 6 (Podel.19G035300), ABC transporter C family member 3-like (Podel.03G215800), probable serine/threonine-protein kinase 
clkA (Podel.03G153500), plant intracellular Ras-group-related LRR protein 3-like (Podel.10G040100), UDP-glucoronosyl/UDP-glucosyl transferase family protein UDP (Podel.04G076900), and random slug protein 5-like (Podel.05G137500). Among them, Podel.03G153500 had the strongest connectivity with all other genes and participates in plant response to stress (Table S5).

The expression levels of most hub genes in the leaves of genotypes A and C decreased slightly in the early stage of low $\mathrm{N}$ stress (from T0 to T2), and increased gradually from T2 to T6. Moreover, the expression levels of hub genes in genotype A were lower than those in genotype $\mathrm{C}$ at $\mathrm{T} 0$, but it was the opposite at $\mathrm{T} 6$, indicating more obvious changes in the expressions of hub genes in genotype A (Fig. 12, Table S4).

To further explore the key genes in the 'magenta' module, TF annotation was carried out. Finally, 12 TFs were annotated (Table S6), including WRKY TF family genes [PodelWRKY41 (Podel.01G096500), PodelWRKY75 (Podel.15G104200), and PodelWRKY18 (Podel.18G019200)], bHLHTF family genes [PodelBHLH25 (Podel.01G303700), PodelBHLH30 (Podel.02G115300), and PodelBHLH (Podel.06G162000)], LOB TF family genes [PodelLBD37 (Podel.07G061600) and PodelLBD1 (Podel.08G051900)], ARR-B TF family genes [PodelWER (Podel.12G083500)], bZIP TF family genes [PodelHY5 (Podel.06G265700)], SBP TF family genes [PodelSPL4 (Podel.01G421600)], and zf-HD TF family genes [PodelZHD4 (Podel.12G042700)]. Among them, the connectivity between PodelWRKY18 and other genes in the 'magenta' module was second only to the hub genes, and the changing trend of its expression with the duration of low $\mathrm{N}$ stress was consistent with that of the hub genes (Fig. 12, Table S6). 

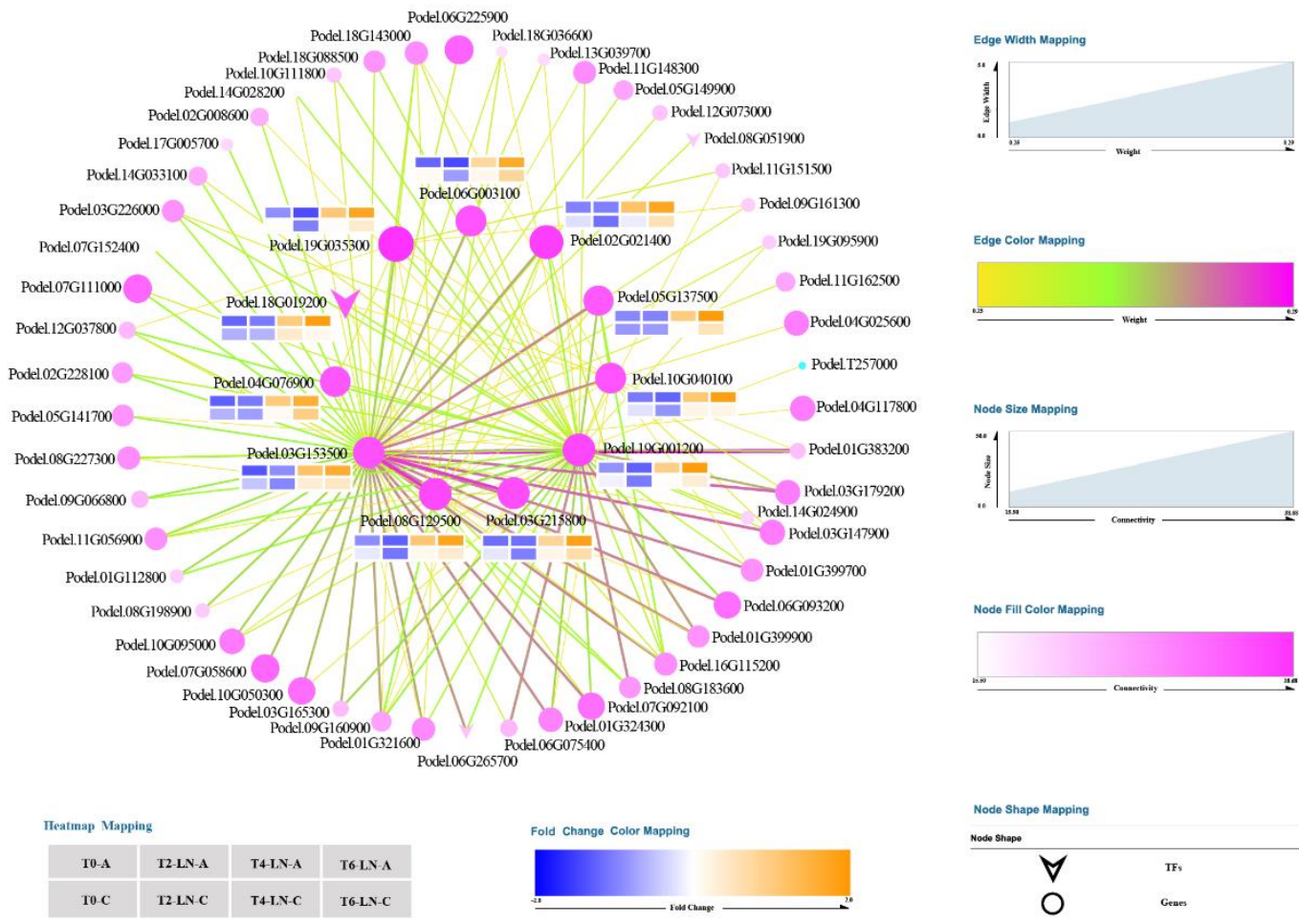

Fig. 12. Cytoscape representation of the top 150 network relationships related to hub genes that were selected according to the weight value in the 'magenta' module. The color of the lines between genes from orange to green to pink indicates that the correlation (weight value) between genes is becoming stronger, and the thicker the lines, the stronger the correlation (weight value). The larger the node, the pinker the color, indicating the greater connectivity of the gene in the module, and TFs represent transcription factors. The heat map next to the central gene shows the expression level of the gene in different samples, and the color from blue to orange indicates that the expression level is increasing. In the upper row, the four samples from left to right are T0-A, T2-LN-A, T4-LN-A, and T6-LN-A, respectively, and in the next row are T0-C, T2-LN-C, T4-LN-C, and T6-LN-C, respectively.

\section{Difference in Gene Expression Related to N Metabolism under N Stress}

The expression levels of genes related to $\mathrm{N}$ uptake, transport, and assimilation in genotypes A and

C during LN treatment were detected using quantitative real-time reverse transcription PCR (qRT-

PCR), and the accuracy of transcriptome data was verified by comparing the results of qRT-PCR and RNA sequencing. In $\mathrm{LN}$ treatment, the expression levels of nitrate $\left(\mathrm{NO}_{3}{ }^{-}\right)$transport related genes [NRT1;1 (Podel.03G118100) and NRT1;2 (Podel.12G073800)] were inhibited, and the change trends in genotypes $\mathrm{A}$ and $\mathrm{C}$ were similar (Fig. S3A,B). The expression of AMT1;6 (Podel.09G046000) was inhibited in genotype A and promoted in genotype C, while the expression 
397

of AMT2;1 (Podel.06G111800) showed the reverse results (Fig. S3C,D). In genotype A, the expression levels of NR (Podel.05G183500) and NiR (Podel.04G146000) decreased at first (from T0 to T4) and then increased (from T4 to T6). In genotype C, these genes were inhibited all the time, but promoted in at T2 and T6 (Fig. S3E,F). In genotypes A and C, the expression of GS2 (Podel.10G024300) was upregulated at T2 and gradually decreased from T2 to T6, to a point was lower than that at T0, and the inhibition in genotype A was stronger than that in genotype C (Fig. $\mathrm{S} 3 \mathrm{G}$ ). The expression of GDH2 (Podel.15G117500) decreased from T0 to T2 and then gradually increased from T2 to T6 in genotype A, with the expression at T6 being higher than that at T0. In genotype $\mathrm{C}$, the expression decreased from T0 to T6 (Fig. S3H).

\section{Discussion}

Although studies on plant responses to low $\mathrm{N}$ stress have been carried out at morphological, physiological and transcriptional levels, most of them were limited to root tissues of a single genotype, such as maize [36], rice [23], and poplar [37]. However, different genotypes show different tolerances to biotic and abiotic stresses, including low $\mathrm{N}$ tolerance $[35,38]$. Comparing the differences between two contrasting genotypes for a specific trait can effectively analyze the regulatory relationship between genes, which is widely used to analyze the molecular mechanism of excellent traits and to identify key regulatory genes. Luo et al. analyzed the differences between two contrasting poplar species [a fast-growing species $(P$. alba $\times$ P. glandulosa, Pg) and a slowgrowing species (P. popularis, Pp)] at the transcriptional level under low $\mathrm{N}$ stress, and found that 18 genes involved in $\mathrm{N}$ metabolism showed stronger responses to transcriptional regulation in the roots and leaves of Pp than in those of Pg [39]. Wang et al. revealed that certain mRNAs and miRNAs 
were differentially expressed between $\mathrm{N}$ stress-insensitive (Nanlin 1388) and $\mathrm{N}$ stress-sensitive (Nanlin 895) poplar clones under low $\mathrm{N}$ stress, and noted that miRNAs play an important role in plant adaptation to low $\mathrm{N}$ [40]. These studies confined themselves to studying a single point in time, whereas in the present study, we explored the morphological differences of two contrasting genotypes of NUE under low N stress and carried out a detailed time-course analysis of enzyme activities and gene expression related to $\mathrm{N}$ metabolism in leaves.

\section{Differences of morphological responses to low $N$ stress}

We believe that $\mathrm{N}$-efficient plants have two characteristics, first, they have a stronger $\mathrm{N}$ absorption capacity than other plants, which is closely related to the growth state and architecture of the root system; second, they can efficiently transform the absorbed organic or inorganic $\mathrm{N}$ into dry matter through biological processes such as assimilation, which mainly depends on the activities of enzymes related to $\mathrm{N}$ metabolism in roots and leaves, and the growth status of leaves [41]. Previous studies found that $\mathrm{N}$-efficient genotypes had a more developed root architecture and larger leaf area than $\mathrm{N}$-inefficient genotypes under low $\mathrm{N}$ stress, and low $\mathrm{N}$ stress stimulates the growth of roots, especially fine roots, in plants with high or low NUE [3, 42-43]. In our study, the growth of Nefficient (A-1, A-2, and A-3) and N-inefficient (C-1, C-2, and C-3) genotypes was inhibited under low $\mathrm{N}$ stress (Fig. 1). We found that compared with $\mathrm{N}$-inefficient genotypes, the growth of $\mathrm{N}$ efficient genotypes was less affected and showed higher tolerance to low $\mathrm{N}$ stress (Table S1). Notably, after 40 days of low N stress treatment, the RFW of N-efficient genotypes increased, while the RDW decreased, indicating that the root architecture experienced adaptive changes, the growth of fine roots increased, and the root absorption capacity was enhanced, while the root growth of N- 
441

inefficient genotypes was significantly inhibited, which affected their root absorption capacity. Meanwhile, leaf growth and morphology-related traits could be used as reliable indicators to evaluate plant NUE [44]. In this study, we found that the leaf area of N-efficient genotypes was larger than that of N-inefficient genotypes under CK or LN treatment (Fig. 2), which enhanced the plants' ability to produce dry matter.

\section{Differences in the physiological responses to low $N$ stress}

As the main component of photosynthetic pigments, in a growing environment, the $\mathrm{N}$ content and its availability in leaves affects the synthesis of photosynthetic pigment [10]. These pigments play an important role in the electron transfer process of leaf photosynthesis, and the intensity of photosynthesis will affect the assimilation efficiency of nutrients and the yield of plants. Our study found that the leaves of both genotypes turned yellow after 40 days of low $\mathrm{N}$ stress, and measurement of the chlorophyll content showed that low $\mathrm{N}$ stress inhibited its synthesis. In addition, under CK or LN treatment, the leaf chlorophyll content of N-efficient genotypes was higher than that of $\mathrm{N}$-inefficient genotypes, and the leaf area of $\mathrm{N}$-efficient genotypes was larger than that of $\mathrm{N}$ inefficient genotypes, indicating that $\mathrm{N}$-efficient genotypes, with a higher NutE, could synthesize more carbon and $\mathrm{N}$ compounds (Fig. 2).

$\mathrm{N}$ metabolism in plants can be summarized as absorption, transport, assimilation, and utilization. Plants absorb inorganic $\mathrm{N}\left(\mathrm{NH}_{4}{ }^{+}\right.$and $\left.\mathrm{NO}_{3}{ }^{-}\right)$from the soil with the help of transporters on the surface of the roots, and some of the $\mathrm{NH}_{4}{ }^{+}$and $\mathrm{NO}_{3}{ }^{-}$are assimilated in the roots, while the other part of the $\mathrm{NH}_{4}{ }^{+}$and most of the $\mathrm{NO}_{3}{ }^{-}$, including part of the organic $\mathrm{N}$, is transported to the leaves for assimilation and utilization. During assimilation, $\mathrm{NO}_{3}{ }^{-}$is transformed into $\mathrm{NH}_{4}{ }^{+}$under 
the action of $\mathrm{NR}$ and NiR. Then, $\mathrm{NH}_{4}{ }^{+}$participates in the synthesis of glutamic acid (Glu) under the catalysis of GS and GOGAT. Alternatively, $\mathrm{NH}_{4}{ }^{+}$and 2-oxoglutarate directly synthesize Glu with the help of GDH. Glu can be further involved in the synthesis of organic substances that are necessary for plant growth [16, 32]. NR, GS, GOGAT, and GDH play important roles in N metabolism and their activities in the leaves of $\mathrm{N}$-efficient and $\mathrm{N}$-inefficient genotypes were inhibited under low $\mathrm{N}$ stress. The decrease of NR and GDH activities in leaves of N-efficient genotypes might be related to the decrease of $\mathrm{NO}_{3}{ }^{-}$and $\mathrm{NH}_{4}{ }^{+}$contents in leaves at the early stage of low $\mathrm{N}$ stress, respectively. With the increase of fine root growth, the absorption capacity of roots was enhanced, and the contents of $\mathrm{NO}_{3}{ }^{-}$and $\mathrm{NH}_{4}{ }^{+}$increased. To maintain the stability of $\mathrm{NO}_{3}{ }^{-}$in plants, NR activity increased gradually, resulting in further increase of $\mathrm{NH}_{4}{ }^{+}$content, after which the GDH activity increased gradually. However, the activities of GS and GOGAT increased briefly during low $\mathrm{N}$ stress, and then decreased thereafter, which indicated that GDH, GS, and GOGAT play an important role in maintaining the balance of $\mathrm{NH}_{4}^{+}$in plants [45]. The difference was that the NR activity was low in the leaves of $\mathrm{N}$-inefficient genotypes, and GDH activity decreased gradually with increasing stress treatment time, which indicated that the assimilation ability in the leaves of the $\mathrm{N}$-inefficient genotype was lower than that of the N-efficient genotypes (Fig. 3).

\section{Differences in transcriptional responses to low $N$ stress and the identification of key genes}

In response to low $\mathrm{N}$ stress, there are many DEGs among plants with different NUE values, which indicates that the molecular mechanisms of their adaptation are different, resulting in different $\mathrm{N}$ absorption and assimilation capacities $[43,46]$. In the present study, the RNA-seq results showed that the responses to low $\mathrm{N}$ stress of the $\mathrm{N}$-efficient and $\mathrm{N}$-inefficient $P$. deltoides genotypes were 
different, and a total of 4,906 DEGs were detected at four-time points, among which the most DEGs were detected at 40 days of treatment (Fig. 4). The unique genes were specificity enriched in multiple pathways, including indole alkaloid biosynthesis and plant hormone signal transduction (Fig. 5), indicating that phytohormones play an important role in the response of plants to low $\mathrm{N}$ stress [46-48]. Meanwhile, we found that compared with the N-efficient genotypes, N-inefficient genotypes were more sensitive to low-N stress; however, fewer DEGs were detected in the process of $\mathrm{N}$ starvation (Fig. 6 and 8). Most of the DEGs detected in all genotypes were enriched in metabolic pathways and the biosynthesis of secondary metabolites, which are related to the plant response to abiotic stress [3]. More genes related to plant hormone signal transduction, and ABC transporters, which are responsible for taking up inorganic $\mathrm{N}$ [8], were specifically detected in the N-efficient genotypes (Fig. 7). Moreover, more genes related to plant-pathogen interactions were found in the leaves of the N-efficient genotypes in response to N starvation (Fig. 9). The differences of genes involved in the response to $\mathrm{N}$ starvation in leaves between the genotypes were closely related to different $\mathrm{N}$ uptake, transport, and assimilation capacities.

To date, key genes closely related to NUE have been found in many plants, such as maize [8], rice [15, 25, 49], oilseed rape [3], and poplar [22, 48]. Wei et al. [22] and Dash et al. [28-29] found that three key genes (PtaHWS, PtaNAC1, and PtaRAP2.11) were highly expressed in poplar (P. tremula $\times P . a l b a$ ) root system under low $\mathrm{N}$ stress, which promoted the growth of plant roots and improved the NUE of the plant. In our study, we found the 'magenta' module, including 171 genes that are mainly involved in the response to stress and negative regulation of many biological processes, was closely and negatively related to the changing trend of GS, GOGAT, and AAs in the leaves of poplar during the response to low N stress (Fig. 10 and 11, Table S3). Meanwhile, 10 hub 
genes and 12 TFs that might play an important role were identified in the module (Fig. 12, Table S4). Among the 10 hub genes, Podel.19G001200, which encodes a protein with a membrane attack complex component/perforin (MACPF) domain [50], and Podel.03G153500, which probable encodes a serine/threonine-protein kinase with a development and cell death (DCD) domain [51], are involved in cell development and programmed cell death. The domain of unknown function 668 (DUF668)-containing protein (Podel.02G021400) [52], the GRAM (from glucosyltransferases, Rab-like GTPase activators and myotubularins) domain-containing protein (Podel.06G003100) [53], and UDP-glycosyltransferases (Podel.04G076900) [54] are essential for plant defense against abiotic stress. The genes mentioned above might play an important role in the response to low $\mathrm{N}$ stress. Previous studies have shown that NUE and signaling pathways are regulated by TFs in response to $\mathrm{N}$ starvation [8, 55-57]. Among the TFs found in this study, WRKY TFs, regulating a variety of hormone signaling pathways [58]; bHLH TFs, one of the largest TF families in plants, regulating plant growth and signal transduction [59]; and bZIP TFs, regulating processes including pathway defense, light, and stress signaling [60], were detected in response to low $\mathrm{N}$ stress. These TFs were identified as being responsive to $\mathrm{N}$ availability in maize [8], Arabidopsis [56], and rice [57]. Moreover, the PodelWRKY18 (Podel.18G019200) was specifically upregulated in N-efficient and $\mathrm{N}$-inefficient genotypes under low $\mathrm{N}$ stress, which was consistent with previously published results [56].

The expressions of $N R T 1 ; 1$ and $N R T 1 ; 2$ in the leaves of the two contrasting genotypes were inhibited under low $\mathrm{N}$ stress. With the increase of treatment time, the expression of $A M T 1 ; 6$ in the leaves of $\mathrm{N}$-efficient genotypes first increased, then decreased, and finally lower than that before treatment, and this change trend was completely opposite to that of $A M T 2 ; 1$. In contrast, the 
expression of $A M T 1 ; 6$ in the leaves of $\mathrm{N}$-inefficient genotype was up-regulated and that of $A M T 2 ; 1$ was down-regulated under low $\mathrm{N}$ condition. The results indicated that there were differences in the absorption and transport mechanism of $\mathrm{NH}_{4}{ }^{+}$between the $\mathrm{N}$-efficient and $\mathrm{N}$-inefficient genotypes. The results of qRT-PCR or RNA-seq of N assimilation-related genes (NR, GS2, and GDH2, Fig. S3) in plant leaves support the changing trend of related enzyme activities (NR, GS, and GDH, Fig. 3). Moreover, we speculated that the upregulation of $A M T 2 ; 1$ in the leaves of the N-efficient genotypes could inhibit GS2 expression and induce $G D H 2$ expression, which is of great significance in maintaining the stability of the $\mathrm{NH}_{4}{ }^{+}$content.

In summary, there were significant differences in the molecular mechanisms between $\mathrm{N}$ efficient and $\mathrm{N}$-inefficient genotypes in response to low $\mathrm{N}$ stress. To the best of our knowledge, this is the first time-course analysis of enzyme activities and gene expression related to $\mathrm{N}$ metabolism in leaves of two contrasting genotypes under low $\mathrm{N}$ stress. The results could provide valuable information to understand the $\mathrm{N}$ efficient assimilation and utilization capacity of $P$. deltoides.

\section{Conclusions}

In the present study, plant growth, chlorophyll synthesis, and enzyme activities related to $\mathrm{N}$ metabolism of $P$. deltoides were inhibited under low $\mathrm{N}$ stress, and the N-efficient genotypes showed stronger adaptability and a better NUE than the N-inefficient genotypes. The time-course analysis of transcriptome data revealed that compared with the $\mathrm{N}$-inefficient genotypes, more genes related to $\mathrm{N}$ assimilation and plant hormone signal transduction were involved in the response to low $\mathrm{N}$ stress in the leaves of N-efficient genotypes, and the sensitivity to $\mathrm{N}$ starvation was weak. Under low $\mathrm{N}$ stress, the upregulated expression of genes related to the negative regulation of the life process 
551

552

553

554

555

556

557

558

559

560

561

562

563

564

565

566

567

in leaves slowed down the life activity of plants and enhanced the defensive ability to cope with $\mathrm{N}$ starvation. The discovery of hub genes (Podel.19G001200, Podel.19G035300, Podel.02G021400, and Podel.04G076900) related to programmed cell death and the defense response, and TFs (WRKY, bHLH, and bZIP) related to signal transduction, provided a valuable theoretical basis for analyzing the molecular mechanism of $\mathrm{N}$ efficient utilization and improving the NUE of poplar.

\section{Methods}

\section{Plant Materials and Treatments}

Based on previous research results, three N-efficient genotypes (A-1, A-2, and A-3) and three Ninefficient genotypes (C-1, C-2, and C-3) of $P$. deltoides were used in this study [35]. One-year-old cuttings (15 cm in length, $1.5 \mathrm{~cm}$ in diameter) of each genotype were rooted and cultured in nutritional pots $(5 \mathrm{~cm}$ in height, $5 \mathrm{~cm}$ in caliber) filled with medium (nutrient soil:perlite $=9: 1$ ). After cultivation for 40 days in a greenhouse at the Chinese Academy of Forestry (400'10" N, $\left.116^{\circ} 14^{\prime} 38^{\prime \prime} \mathrm{E}\right), 40$ uniform plants of each genotype were selected and the root systems of the plants were carefully washed with running water. The plants were then cultured with water in new pots (20 $\mathrm{cm}$ in height, $10 \mathrm{~cm}$ in caliber) filled with vermiculite for 15 days. Subsequently, the plants were irrigated every other day with $100 \mathrm{ml}$ of one-tenth strength Hoagland nutrient solution, which contained $0.5 \mathrm{mM} \mathrm{KNO}_{3}, 0.4 \mathrm{mM} \mathrm{Ca}\left(\mathrm{NO}_{3}\right)_{2} \cdot 4 \mathrm{H}_{2} \mathrm{O}, 0.4 \mathrm{mM} \mathrm{MgSO} \cdot \cdot 7 \mathrm{H}_{2} \mathrm{O}, 0.1 \mathrm{mM} \mathrm{NH}_{4} \mathrm{NO}_{3}, 0.1$ $\mathrm{mM} \mathrm{KH}_{2} \mathrm{PO}_{4}, 5 \mu \mathrm{M} \mathrm{Fe}-\mathrm{EDTA}(\mathrm{pH}=5.5), 50 \mathrm{nM} \mathrm{H}_{3} \mathrm{BO}_{3}, 50 \mathrm{nM} \mathrm{MnSO}_{4} \cdot 4 \mathrm{H}_{2} \mathrm{O}, 15 \mathrm{nM} \mathrm{ZnSO} \cdot 7 \mathrm{H}_{2} \mathrm{O}$, $2.5 \mathrm{nM} \mathrm{KI}, 0.5 \mathrm{nM} \mathrm{Na}_{2} \mathrm{MoO}_{4} \cdot 2 \mathrm{H}_{2} \mathrm{O}, 0.05 \mathrm{nM} \mathrm{CuSO}_{4} \cdot 5 \mathrm{H}_{2} \mathrm{O}$, and $0.05 \mathrm{nM} \mathrm{CoCl}_{2}$. The solution was adjusted to $\mathrm{pH}$ 6.0. After 20 days, 30 plants from each genotype were selected and randomly divided into two groups (15 plants in each group) for $\mathrm{N}$ treatment. Plants of the two groups were cultivated 
573

574

575

with modified Hoagland nutrient solution $\left(0.5 \mathrm{mM} \mathrm{KCl}, 0.4 \mathrm{mM} \mathrm{CaCl} \cdot 2 \mathrm{H}_{2} \mathrm{O}, 0.4 \mathrm{mM}\right.$ $\mathrm{MgSO}_{4} \cdot 7 \mathrm{H}_{2} \mathrm{O}, 0.1 \mathrm{mM} \mathrm{KH} \mathrm{PO}_{4}, 5 \mu \mathrm{M}$ Fe-EDTA $[\mathrm{pH}=5.5], 50 \mathrm{nM} \mathrm{H}_{3} \mathrm{BO}_{3}, 50 \mathrm{nM} \mathrm{MnSO} \mathrm{M}_{4} \cdot 4 \mathrm{H}_{2} \mathrm{O}$, $15 \mathrm{nM} \mathrm{ZnSO} 4 \cdot 7 \mathrm{H}_{2} \mathrm{O}, 2.5 \mathrm{nM} \mathrm{KI}, 0.5 \mathrm{nM} \mathrm{Na} \mathrm{MoO}_{4} \cdot 2 \mathrm{H}_{2} \mathrm{O}, 0.05 \mathrm{nM} \mathrm{CuSO} \cdot 5 \mathrm{H}_{2} \mathrm{O}$, and $0.05 \mathrm{nM}$ $\mathrm{CoCl}_{2}$ ) containing $5 \mu \mathrm{M}(\mathrm{LN})$ or $750 \mu \mathrm{M}(\mathrm{CK}) \mathrm{NH}_{4} \mathrm{NO}_{3}$, respectively, every two days. The $\mathrm{N}$ treatments were maintained for 40 days before harvest.

\section{Sample Collection}

The leaves of each genotype were sampled at 0 (T0), 3 (T1), 5 (T2), 10 (T3), 20 (T4), 30 (T5), and 40 (T6) days of N-treatment. Three biological repeats were taken for each genotype in the LN or CK treatment, and each replicate included 2-3 mature functional leaves. The sampling time was between 9:00 am and 10:00 am. A mixed leaf sample was obtained by mixing one biological repeat leaf sample of the three $\mathrm{N}$-efficient genotypes or $\mathrm{N}$-inefficient genotypes at the same time point in the same $\mathrm{N}$ treatment. Finally, at each time point of each treatment, there were three mixed samples for the two NUE type plants, respectively. These mixed samples were stored at $-80{ }^{\circ} \mathrm{C}$ for the determination of enzyme activities related to $\mathrm{N}$ metabolism and for transcriptome sequencing.

\section{Enzyme Activity Assay}

The activities of nitrate reductase (NR, EC 1.7.1.3), glutamine synthetase (GS, EC 6.3.1.2), glutamic acid synthetase (GOGAT, EC 1.4.7.1), and glutamate dehydrogenase (GDH, EC 1.4.1.2) in the mixed leaf samples were detected using the relevant biochemical kits (BC0085, BC0915, BC0075, and $\mathrm{BC} 1465$, respectively, Solarbio, Beijing, China). The detection steps followed the manufacturer's instruction strictly. 
The contents of free amino acids (AAs) and soluble sugars (SSs) in mixed samples of leaves were determined using the corresponding biochemical kits (BC1575 and BC0035, respectively, Solarbio) according to the manufacturer's protocol.

\section{RNA Extraction, Library Construction, and Sequencing}

Total RNA was extracted from leaves using a Trizol reagent kit (Invitrogen, Carlsbad, CA, USA). RNA purity was detected using a Nanodrop 2000 microspectrophotometer (Thermo Fisher, Waltham, MA, USA), and the RNA quality was assessed on an Agilent 2100 Bioanalyzer (Agilent Technologies, Palo Alto, CA, USA) and checked using RNase free agarose gel electrophoresis. Sequencing libraries were constructed using a NEBNext Ultra RNA Library Prep Kit for Illumina (\#E7530, NEB, Ipswich, MA, USA) according to the manufacturer's instructions. Sequencing was performed using Illumina NovaSeq 6000 by Gene Denovo Biotechnology Co. (Guangzhou, China).

\section{RNA Sequencing Data Analysis}

The raw reads were filtered using fastp v0.18.0 [61] to obtain high-quality clean reads, and the clean reads were mapped to the reference genome of P. deltoides (JGI 2.1) using HISAT2. 2.4 [62]. The mapped reads of each mixed sample were assembled using StringTie v1.3.1 [63-64]. For each transcription region, the FPKM (fragment per kilobase of transcript per million mapped reads) value was calculated to quantify its expression abundance using StringTie software. DEGs between two different samples were screened with the parameters of a false discovery rate (FDR) below 0.05 and absolute fold change $>2$ using DESeq2 software [65]. First, the differences in the expression of 
mixed samples between $\mathrm{N}$-efficient and $\mathrm{N}$-inefficient genotypes were compared at the same time point in the LN treatment. Then, the differences in gene expression of $\mathrm{N}$-efficient or $\mathrm{N}$-inefficient genotypes at different time points during LN treatment were studied. All DEGs were mapped to GO terms in the database: http://www.geneontology.org/ [66]. A calculated $p$-value $<0.05$ defined a significantly enriched GO term for the DEGs. Pathway enrichment analysis was performed to test the statistical enrichment of DEGs in the KEGG pathways [67]. KEGG pathways with a corrected $p$-value $<0.05$ were considered as significantly enriched pathways for the DEGs. WGCNA was performed using the 'WGCNA (v1.47)' package in R to find modules of highly correlated genes and to relate the modules to specific traits [68]. The relationship network between selected DEGs was visualized with the help of Cytoscape (v 3.7.1) software [69]. Bioinformatic analysis of transcriptome data was performed using Omicsmart, a real-time interactive online platform for data analysis (http://www.omicsmart.com).

\section{Quantitative Real-Time PCR Analysis}

The qRT-PCR was conducted for genes related to $\mathrm{N}$ metabolism $(N R T 1 ; 1, N R T 1 ; 2, A M T 1 ; 6$, $A M T 2 ; 1, N R, N i R, G S 2$, and $G D H 2$ ) using total RNA extracted from three biological repeats of mixed samples. The TB Green Premix Ex Taq II (Takara, Dalian, China) was used to perform the quantitative real-time PCR step of qRT-PCR in a LightCycler 480 Instrument II system (Roche, Basel, Switzerland). The PCR conditions were as follows: $95{ }^{\circ} \mathrm{C}$ for $30 \mathrm{~s} ; 40$ cycles of $95{ }^{\circ} \mathrm{C}$ for 5 $\mathrm{s}$ and $60^{\circ} \mathrm{C}$ for $30 \mathrm{~s}$; followed by $95^{\circ} \mathrm{C}$ for $5 \mathrm{~s}$ and $60^{\circ} \mathrm{C}$ for $1 \mathrm{~min}$. The reaction system is listed in Table S7. Actin 2/7 was used as an internal reference, and relative expression levels were calculated using the $2^{-\Delta \Delta \mathrm{Ct}}$ method [70]. The gene-specific primer pairs are listed in Table S8. The accuracy of 
transcriptome sequencing data was tested based on the results of qRT-PCR.

\section{Determination of Leaf Morphological Characteristics and Plant Biomass}

The height and the ground diameter of each plant were determined before the $\mathrm{N}$ treatments ( $\mathrm{H} 0$ and GD0) and at harvest (Hn and GDn), respectively. After $\mathrm{N}$ treatment (40 days), three plants whose height was similar to the mean height were selected for each genotype in each treatment. Three to five mature and complete functional leaves per plant were obtained, and the leaf morphological characteristics (leaf length, leaf width, and leaf area) were measured using a leaf area meter (Yaxin1241, Beijing Yaxin Liyi Technology Co., Ltd., Beijing, China). The root system of each plant was carefully washed and collected. The fresh weights of the stem, root, and leaves of each selected plant were recorded. Subsequently, they were dried at $75{ }^{\circ} \mathrm{C}$ for $96 \mathrm{~h}$ until their weights were constant, and then their dry weights were recorded. Finally, to facilitate comparative analysis, the data related to the leaves were transformed into single leaf data.

\section{Measurement of Leaf Chlorophyll}

After $\mathrm{N}$ treatment, the concentrations of chlorophyll in the leaves were measured using the $96 \%$ ethanol method [71], and a total of three biological repeats of each genotype were tested in the LN or CK groups. The method was as follows: The $0.10 \mathrm{~g}$ leaf sample was accurately weighed and put into a $5 \mathrm{ml}$ centrifuge tube, and $4 \mathrm{ml}$ of $96 \%$ ethanol was added to extract chlorophyll from the leaves. After the chlorophyll in the leaves was completely extracted (about 6 hours in darkness), the absorbance values at $470 \mathrm{~nm}, 649 \mathrm{~nm}$, and $665 \mathrm{~nm}$ were measured using Molecular Devices spectrophotometer (Thermo Fisher, Waltham, MA, USA). The concentration of chlorophyll in the 
extract was calculated using formulae 1-4.

$$
\begin{gathered}
\mathrm{C}_{\mathrm{a}}\left(\mathrm{mg} \cdot \mathrm{L}^{-1}\right)=13.95 A_{665}-6.88 A_{649} \\
\mathrm{C}_{\mathrm{b}}\left(\mathrm{mg} \cdot \mathrm{L}^{-1}\right)=24.96 A_{649}-7.32 A_{665} \\
\operatorname{Car}\left(\mathrm{mg} \cdot \mathrm{L}^{-1}\right)=\frac{1000 A_{470}-2.05 \mathrm{C}_{\mathrm{a}}-114.8 \mathrm{C}_{\mathrm{b}}}{245} \\
\mathrm{C}_{\mathrm{T}}\left(\mathrm{mg} \cdot \mathrm{L}^{-1}\right)=\mathrm{C}_{\mathrm{a}}+\mathrm{C}_{\mathrm{b}}
\end{gathered}
$$

Where $A_{470}, A_{649}$, and $A_{665}$ represent the absorbance values at $470 \mathrm{~nm}, 649 \mathrm{~nm}$, and $665 \mathrm{~nm}$ respectively; and $\mathrm{C}_{\mathrm{a}}, \mathrm{C}_{\mathrm{b}}$, Car, and $\mathrm{C}_{\mathrm{T}}$ represent the concentrations of chlorophyll a, chlorophyll $\mathrm{b}$, carotenoids, and total chlorophyll in the extract, respectively.

The content of chlorophyll in leaves was calculated using formula 5.

$$
\text { Chl (mg. } \left.{ }^{-1} \mathrm{FW}\right)=\frac{\mathrm{C}\left(\mathrm{mg} \cdot \mathrm{L}^{-1}\right) \times \mathrm{V}(\mathrm{L})}{\mathrm{m}(\mathrm{g})}
$$

Where $\mathrm{C}$ is the concentration of chlorophyll; $\mathrm{V}$ is the volume of the extract; $\mathrm{m}$ is the fresh weight of the tested leaves; $\mathrm{Chl}$ is the amount of chlorophyll (mg) in $1 \mathrm{~g}$ fresh leaves. Chl a, Chl b, Car, and $\mathrm{Chl}$ are used to represent the contents of chlorophyll a, chlorophyll b, carotenoids, and total chlorophyll, respectively.

\section{Statistical Analyses}

All experiments performed in this study were performed using three biological repeats and three experimental repeats. The phenotypic, physiological, and qRT-PCR data were recorded using Microsoft Excel (Microsoft Corporation, Redmond, WA, USA), and the mean and standard deviation (SD) values of every parameter of each genotype in LN or CK treatment were calculated.

The ratio of the measured values of characteristics under LN treatment and that under CK treatment was used as the LNAC of the plants, which was used to evaluate the adaptability of plant traits to 
679

680

681

682

683

684

685

686

687

688

689

690

691

692

693

694

695

696

697

698

699

700

701

702

703

704

705

706

low N conditions. Differences between different comparison groups were determined using oneway analysis of variance (ANOVA) concatenated with Duncan test $(p<0.05)$ using the package 'agricolae' in R (v 3.5.3).

\section{Abbreviations}

N: nitrogen; A: N-efficient genotypes; C:N-inefficient genotypes; LN: low nitrogen treatment; CK: normal nitrogen supply treatment; Hn: height after treatment; GDn: ground diameter after treatment; SFW: fresh weight of the stem; SDW: dry weight of the stem; RFW: fresh weight of the root; RDW: dry weight of the root; LFW: fresh weight of the leaf; LDW: dry weight of the leaf; Chl a: chlorophyll a; Chl b: chlorophyll b; Car: carotenoid; Chl: chlorophyll (a+b); LL: leaf length; LW: leaf width; LA: leaf area; NR: nitrate reductase activities; GS: glutamine synthetase activities; GDH: glutamate dehydrogenase activities; GOGAT: glutamic acid synthetase activities; AAs: total amino acid contents; SSs: soluble sugar contents; DEG: differentially expressed gene; GO: gene ontology; KEGG: Kyoto Encyclopedia of Genes and Genomes; WGCNA: weighted gene co-expression network analysis.

\section{Declarations}

\section{Availability of Data}

The sequence data reported in this paper have been deposited in the Genome Sequence Archive [72] in National Genomics Data Center [73], Beijing Institute of Genomics (China National Center for Bioinformation), Chinese Academy of Sciences, under accession number CRA003529 that are publicly accessible at https://bigd.big.ac.cn/gsa.

\section{Authors' contributions}

Conceptualization, XS and YC; Methodology, CC and YC; Sample cultivation, CC, JZ and BL;

Sample and data collection, CC, JZ, BL, TZ and ZL; Critical contribution in analysis, CC, CD, WZ,

QH and YC; Contributed to writing the manuscript: CC, YC, QH and XS; Project administration, YC; Supervision, XS. All authors have read and agreed to the published version of the manuscript. 
Funding

709 This research was funded by the National Natural Science Foundation of China (Grant No.

710 31670677), and the Basic Research Fund of RIF (Grant No. CAFYBB2020SZ002 and

711

712

713

714

715

716

717

718

719

720

721

722

723

724

725

726

727

728

729

730

CAFYBB2017ZA001-3).

\section{Acknowledgments:}

The authors would like to thank funders for funding this research and the State Key Laboratory of Tree Genetics and Breeding, Research Institute of Forestry, Chinese Academy of Forestry for the instrument support.

\section{Competing interests}

The authors declare no conflict of interests.

\section{Ethics approval and consent to participate}

Not applicable.

\section{Consent for publication}

Not applicable.

\section{References}

1. Frink CR, Waggoner PE, Ausubel JH. Nitrogen fertilizer: Retrospect and prospect. Proc Natl Acad Sci USA. 1999;96:1175-1180.

2. Cánovas FM, Cañas RA, de la Torre FN, Pascual MB, Castro-Rodríguez V, Avila C. Nitrogen 
metabolism and biomass production in forest trees. Front Plant Sci. 2018;9:1449.

3. Tang WJ, He X, Qian LW, Wang F, Zhang ZH, Sun C, Lin LB, Guan CY. Comparative transcriptome analysis in oilseed rape (Brassica napus) reveals distinct gene expression details between nitrate and ammonium nutrition. Genes. 2019;10:391.

4. Kaur G, Asthir B, Bains NS, Farooq M. Nitrogen nutrition, its assimilation and remobilization in diverse wheat genotypes. Int J Agric Biol. 2015;17:531-538.

5. Zhu ZL, Chen DL. Nitrogen fertilizer use in China - contributions to food production, impacts on the environment and best management strategies. Nutr Cycl Agroecosystems. 2002; 63:117-127.

6. Li H, Hu B, Chu CC. Nitrogen use efficiency in crops: Lessons from Arabidopsis and rice. J Exp Bot. 2017;68:2477-2488.

7. Boyle E. 2017; . Nitrogen pollution knows no bounds. Science. 2012;356:700-701.

8. Jiang L, Ball G, Hodgman C, Coules A, Zhao H, Lu CG. Analysis of gene regulatory networks of Maize in response to nitrogen. Genes. 2018;9:151.

9. Hawkesford MJ, Griffths S. Exploiting genetic variation in nitrogen use efficiency for cereal crop improvement. Curr Opin Plant Biol. 2019;49:35-42.

10. Sinha SK, Sevanthi V AM, Chaudhary S, Tyagi P, Venkadesan S, Rani M, Mandal PK. Transcriptome analysis of two rice varieties contrasting for nitrogen use efficiency under chronic $\mathrm{N}$ starvation reveals differences in chloroplast and starch metabolism-related genes. Genes. 2018;9:206.

11. Garnett T, Plett D, Conn V, Conn S, Rabie H, Rafalski JA, Dhugga K, Tester MA, Kaiser BN. Variation for $\mathrm{N}$ uptake system in maize: genotypic response to $\mathrm{N}$ supply. Front Plant Sci. 2015;6:936.

12. Qin L, Walk TC, Han PP, Chen LY, Zhang S, Li YS, Hu XJ, Xie LH, Yang Y, Liu JP, Lu X, Yu CB, Tian J, Shaff JE, Kochian LV, Liao X, Liao H. Adaption of roots to nitrogen deficiency revealed by 3D quantification and proteomic analysis. Plant Physiol. 2019;179:329-347.

13. Rennenberg H, Dannenmann M, Gessler A, Kreuzwieser J, Simon J, Papen H. Nitrogen balance in forest soils: nutritional limitation of plants under climate change stresses. Plant Biol. 2009;11:4-23.

14. Tegeder M, Masclaux-Daubresse C. Source and sink mechanisms of nitrogen transport and use. New Phytol. 2018;217:35-53.

15. Hu B, Wang W, Ou SJ, Tang JY, Li H, Che RH, Zhang ZH, Chai XY, Wang HR, Wang YQ, Liang CZ, Liu LC, Piao ZZ, Deng QY, Deng K, Xu C, Liang Y, Zhang LH, Li LG, Chu CC. Variation in NRT1.1B contributes to nitrate-use divergence between rice subspecies. Nat Genet. $2015 ; 47: 834$.

16. Xu G, Fan X, Miller AJ. Plant nitrogen assimilation and use efficiency. Annu Rev Plant Biol. 2012;63:153-182.

17. Ellis RP, Forster BP, Robinson D, Handley LL, Gordon DC, Russell JR, Powell W. Wild barley: a source of genes for crop improvement in the 21 st century? J Exp Bot. 2000;51:9-17.

18. Good AG, Shrawat AK, Muench DG. Can less yield more? Is reducing nutrient input into the environment compatible with maintaining crop production? Trends Plant Sci. 2004;9:597-605.

19. Wang Z, Gerstein M, Snyder M. RNA-Seq: A revolutionary tool for transcriptomics. Nat Rev Genet. 2009;10:57-63.

20. Yang SY, Hao DL, Song ZZ, Yang GZ, Wang L, Su YH. RNA-seq analysis of differentially expressed genes in rice under varied nitrogen supplies. Gene. 2015;555:305-317. 
21. Rawal HC, Kumar S, Mithra SVA, Solanke AU. High quality unigenes and microsatellite markers from tissue specific transcriptome and development of a database in Clusterbean (Cyamopsis tetragonoloba, L. Taub). Genes. 2017;8:313.

22. Wei HR, Yordanov YS, Georgieva T, Li X, Busov V. Nitrogen deprivation promotes Populus root growth through global transcriptome reprogramming and activation of hierarchical genetic networks. New Phytol. 2013;200:483-497.

23. Yang WZ, Yoon J, Choi H, Fan YL, Chen RM, An G. Transcriptome analysis of nitrogenstarvation-responsive genes in rice. BMC Plant Biol. 2015;15:31.

24. Li W, Xiang F, Zhong MC, Zhou LY, Liu HY, Li SJ, Wang XW. Transcriptome and metabolite analysis identifies nitrogen utilization genes in tea plant (Camellia sinensis). Sci Rep. 2017;7:1693.

25. Subudhi PK, Garcia RS, Coronejo S, Tapia R. Comparative transcriptomics of rice genotypes with contrasting responses to nitrogen stress reveals genes influencing nitrogen uptake through the regulation of root architecture. Int J Mol Sci. 2020;21:5759.

26. Zhang XX, Zhou J, Huang NS, Mo LJ, Lv MJ, Gao YB, Chen C, Yin SY, Ju J, Dong GC, Zhou Y, Yang ZF, Li AH, Wang YL, Huang JY, Yao YL. Transcriptomic and co-expression network profiling of shoot apical meristem reveal contrasting response to nitrogen rate between Indica and Japonica rice subspecies. Int J Mol Sci. 2019;20:5922.

27. Marbach D, Costello JC, Küffner R, Vega NM, Prill RJ, Camacho DM, Allison KR, Kellis M, Collins JJ, Stolovitzky G. Wisdom of crowds for robust gene network inference. Nat Methods. 2012;9:796-804.

28. Dash M, Yordanov YS, Georgieva T, Kumari S, Wei H, Busov V. A systems biology approach identifies new regulators of poplar root development under low nitrogen. Plant J. 2015;84:335346.

29. Dash M, Yordanov YS, Georgieva T, Kumari S, Wei H, Busov V. A network of genes associated with poplar root development in response to low nitrogen. Plant Signal Behav. 2016;11:e1214792.

30. Zhang F, Wang LY, Bai PX, Wei K, Zhang YZ, Ruan L, Wu LY, Cheng H. Identification of regulatory networks and hub genes controlling nitrogen uptake in tea plants [Camellia sinensis (L.) O. Kuntze]. J Agric Food Chem. 2020;68:2445-2456.

31. Gu X, Yang S, Yang XH, Yao LL, Gao XD, Zhang MM, Liu W, Zhao HH, Wang QS, Li ZJ, Li ZM, Ding JJ. Comparative transcriptome analysis of two Cercospora sojina strains reveals differences in virulence under nitrogen starvation stress. BMC Microbiol. 2020;20:166.

32. Rennenberg H, Wildhagen H, Ehlting B. Nitrogen nutrition of poplar trees. Plant Biol. 2010;12:275-291.

33. Balasus A, Bischoff WA, Schwarz A, Scholz V, Kern J. Nitrogen fluxes during the initial stage of willows and poplars in short-rotation coppices. J Plant Nutr Soil Sci. 2012;175:729-738.

34. Chen C, Chu YG, Ding CJ, Su XH, Huang QJ. Genetic diversity and population structure of black cottonwood (Populus deltoides) revealed using simple sequence repeat markers. BMC Genet. 2020;21:2.

35. Chen C, Chu YG, Huang QJ, Ding CJ, Zhang WX, Li B, Zhang J, Su XH. Morphological and physiological plasticity of response to low nitrogen stress in black cottonwood (Populus deltoides Marsh.) population. J For Res. 2020. (in press).

36. Tadesse Ertiro B, Olsen M, Das B, Gowda M, Labuschagne M. Genetic dissection of grain yield and agronomic traits in maize under optimum and low-nitrogen stressed environments. Int $\mathrm{J}$ Mol 
Sci. 2020;21:543.

37. Zhang CX, Meng S, Li MJ, Zhao Z. Transcriptomic insight into nitrogen uptake and metabolism of Populus simonii in response to drought and low nitrogen stresses. Tree Physiol. 2018;38:16721684.

38. Kalcsits LA, Guy RD. Genotypic variation in nitrogen isotope discrimination in Populus balsamifera L. clones grown with either nitrate or ammonium. J Plant Physiol. 2016;201:54-61.

39. Luo J, Li H, Liu TX, Polle A, Peng CH, Luo ZB. Nitrogen metabolism of two contrasting poplar species during acclimation to limiting nitrogen availability. J Exp Bot. 2013;64:4207-4224.

40. Wang XL, Li XD, Zhang S, Korpelainen H, Li CY. Physiological and transcriptional responses of two contrasting Populus clones to nitrogen stress. Tree Physiol. 2016;36:628-642.

41. Moll RH, Kamprath EJ, Jackson WA. Analysis and interpretation of factors which contribute to efficiency of nitrogen utilization. Agron J. 1982;74:562-568.

42. Quan XY, Qian QF, Ye ZL, Zeng JB, Han ZG, Zhang GP. Metabolic analysis of two contrasting wild barley genotypes grown hydroponically reveals adaptive strategies in response to low nitrogen stress. J Plant Physiol. 2016;206:59-67.

43. Meng S, Wang S, Quan J, Su WL, Lian CL, Wang DL, Xia X, Yin WL. Distinct carbon and nitrogen metabolism of two contrasting poplar species in response to different $\mathrm{N}$ supply levels. Int J Mol Sci. 2018;19:2302.

44. Mao QG, Lu XK, Mo H, Gundersen P, Mo JM. Effects of simulated N deposition on foliar nutrient status, $\mathrm{N}$ metabolism and photosynthetic capacity of three dominant understory plant species in a mature tropical forest. Sci Total Environ. 2018;610-611:555-562.

45. Forde BG, Lea PJ. Glutamate in plants: Metabolism, regulation, and signalling. J Exp Bot. 2007;58:2339-2358.

46. Luo J, Zhou J, Li H, Shi WG, Polle A, Lu MZ, Sun XM, Luo ZB. Global poplar root and leaf transcriptomes reveal links between growth and stress responses under nitrogen starvation and excess. Tree Physiol. 2015;35:1283-1302.

47. Luo L, Zhang Y, Xu G. How does nitrogen shape plant architecture? J Exp Bot. 2020;71:44154427.

48. Lu Y, Deng SR, Li ZR, Wu JT, Liu QF, Liu WZ, Yu WJ, Zhang YH, Shi WG, Zhou J, Li H, Polle A, Luo ZB. Competing endogenous RNA networks underlying anatomical and physiological characteristics of poplar wood in acclimation to low nitrogen availability. Plant Cell Physiol. 2019;60:2478-2495.

49. Ueda Y, Ohtsuki N, Kadota K, Tezuka A, Nagano AJ, Kadowaki T, Kim Y, Miyao M, Yanagisawa S. Gene regulatory network and its constituent transcription factors that control nitrogendeficiency responses in rice. New Phytol. 2020;227:1434-1452.

50. Fukunaga S, Sogame M, Hata M, Singkaravanit-Ogawa S, Piślewska-Bednarek M, OnozawaKomori M, Nishiuchi T, Hiruma K, Saitoh H, Terauchi R, Kitakura S, Inoue Y, Bednarek P, Schulze-Lefert P, Takano Y. Dysfunction of Arabidopsis MACPF domain protein activates programmed cell death via tryptophan metabolism in MAMP-triggered immunity. Plant J. 2017;89:381-393.

51. Tenhaken R, Doerks T, Bork P. DCD-a novel plant specific domain in proteins involved in development and programmed cell death. BMC Bioinformatics. 2005;6:169.

52. Zhong H, Zhang HY, Guo R, Wang Q, Huang XP, Liao JL, Li YS, Huang YJ, Wang ZH. Characterization and functional divergence of a novel DUF668 gene family in rice based on 
comprehensive expression patterns. Genes. 2019; 10:980.

53. Tiwari S, Shweta S, Prasad M, Lata C. Genome-wide investigation of GRAM-domain containing genes in rice reveals their role in plant-rhizobacteria interactions and abiotic stress responses. Int J Biol Macromol. 2020;156:1243-1257.

54. Li P, Li YJ, Zhang FJ, Zhang GZ, Jiang XY, Yu HM, Hou BK. The Arabidopsis UDPglycosyltransferases UGT79B2 and UGT79B3, contribute to cold, salt and drought stress tolerance via modulating anthocyanin accumulation. Plant J. 2017;89:85-103.

55. Kurai T, Wakayama M, Abiko T, Yanagisawa S, Aoki N, Ohsugi R. Introduction of the ZmDofl gene into rice enhances carbon and nitrogen assimilation under low-nitrogen conditions. Plant Biotechnol J. 2011;9:826-837.

56. Heerah S, Katari MS, Penjor R, Coruzzi GM, Marshall-Colon A. WRKY1 mediates transcriptional regulation of light and nitrogen signaling pathways. Plant Physiol. 2019;181:13711388.

57. Xin W, Zhang LN, Zhang WZ, Gao JP, Yi J, Zhen XX, Du M, Zhao YZ, Chen LQ. An integrated analysis of the rice transcriptome and metabolome reveals root growth regulation mechanisms in response to nitrogen availability. Int J Mol Sci. 2019;20:5893.

58. Jiang JJ, Ma SH, Ye NH, Jiang M, Cao JS, Zhang JH. WRKY transcription factors in plant responses to stresses. J Integr Plant Biol. 2017;59:86-101.

59. Sun X, Wang Y, Sui N. Transcriptional regulation of bHLH during plant response to stress. Biochem Biophys Res Commun. 2018;503:397-401.

60. Jakoby M, Weisshaar B, Dröge-Laser W, Vicente-Carbajosa J, Tiedemann J, Kroj T, Parcy F, bZIP Research Group. bZIP transcription factors in Arabidopsis. Trends Plant Sci. 2002;7:106111.

61. Chen SF, Zhou YQ, Chen YR, Gu J. fastp: an ultra-fast all-in-one FASTQ preprocessor. Bioinformatics. 2018;34:i884-i890.

62. Kim D, Langmead B, Salzberg SL. HISAT: a fast spliced aligner with low memory requirements. Nat methods. 2015;12:357.

63. Pertea M, Pertea GM, Antonescu CM, Chang TC, Mendell JT, Salzberg SL. StringTie enables improved reconstruction of a transcriptome from RNA-seq reads. Nat Biotechnol. 2015;33:290.

64. Pertea M, Kim D, Pertea GM, Leek JT, Salzberg SL. Transcript-level expression analysis of RNA-seq experiments with HISAT, StringTie and Ballgown. Nat Protoc. 2016;11:1650.

65. Love MI, Huber W, Anders S. Moderated estimation of fold change and dispersion for RNA-seq data with DESeq2. Genome Biol. 2014;15:550.

66. Ashburner M, Ball CA, Blake JA, Botstein D, Butler H, Cherry JM, Davis AP, Dolinski K, Dwight SS, Eppig JT, Harris MA, Hill DP, Issel-Tarver L, Kasarskis A, Lewis S, Matese JC, Richardson JE, Ringwald M, Rubin GM, Sherlock G. Gene ontology: tool for the unification of biology. The Gene Ontology Consortium. Nat Genet. 2000;25:25-29.

67. Kanehisa M, Goto S. KEGG: kyoto encyclopedia of genes and genomes. Nucleic Acids Res. 2000;28:27-30.

68. Langfelder P, Horvath S. WGCNA: an R package for weighted correlation network analysis. BMC Bioinformatics. 2008;9:559.

69. Shannon P, Markiel A, Ozier O, Baliga NS, Wang JT, Ramage D, Amin N, Schwikowski B, Ideker T. Cytoscape: a software environment for integrated models of biomolecular interaction networks. Genome Res. 2003;13:2498-2504. 
70. Schmittgen TD, Livak KJ. Analyzing real-time PCR data by the comparative CT method. Nat Protoc. 2008;3:1101-1108.

71. Lichtenthaler HK, Wellburn AR. Determinations of total carotenoids and chlorophylls a and b of leaf extracts in different solvents. Biochem Soc Trans. 1983;11:591-592.

72. Wang YQ, Song FH, Zhu JW, Zhang SS, Yang YD, Chen TT, Tang BX, Dong LL, Ding N, Zhang Q, Bai ZX, Dong XN, Chen HX, Sun MY, Zhai S, Sun YB, Yu L, Lan L, Xiao JF, Fang XD, Lei HX, Zhang Z, Zhao WM. GSA: Genome Sequence Archive. Genom Proteom Bioinf. 2017;15:14-18.

73. Data Center Members. BIG The BIG Data Center: from deposition to integration to translation. Nucleic Acids Res. 2017;45:D18-D24.

\section{Additional files}

Additional file 1: Table S1. Low nitrogen adaptation coefficients of traits of N-efficient and Ninefficient genotypes. Table S2. Results of quality analysis of RNA sequencing data. Table S3. Results of the GO functional enrichment analysis of genes in the 'magenta' module. Table S4. Genes in the 'magenta' module. Table S5. Annotation description of the top 10 genes for connectivity (hub genes) in the 'magenta' module. Table S6. Annotation of transcription factors in the 'magenta' module. Table S7. The reaction system of quantitative real-time reverse transcription PCR (qRTPCR). Table S8. Primers used for quantitative real-time reverse transcription PCR (qRT-PCR) analysis.

Additional file 2: Fig. S1. Transcriptome relationships among three biological replicates. A: Nefficient genotypes; C: N-inefficient genotypes. T0, T2, T4, and T6 represent $0,5,20$, and 40 days of N treatment, respectively. LN: low N treatment. Fig. S2. Expression pattern analysis of genes in the 'magenta' module. Red: upregulated; blue: downregulated. A: N-efficient genotypes; C: Ninefficient genotypes. T0, T2, T4, and T6 represent $0,5,20$, and 40 days of $\mathrm{N}$ treatment, respectively. LN: low N treatment. Fig. S3. Expression of key genes in nitrogen metabolism in the leaves of genotypes A and C. (A), (B), (C), (D), (E), (F), (G) and (H) represent the expression trends of NRT1;1, NRT1;2, AMT1;6, AMT2;1, NR, NiR, GS2, and GDH2, respectively. The columns represent the results of RNA sequencing, and the lines show the analysis results of qRT-PCR. Vertical bars indicate SDs $(n=3)$ in qRT-PCR analysis. A: N-efficient genotypes; C: N-inefficient genotypes. 

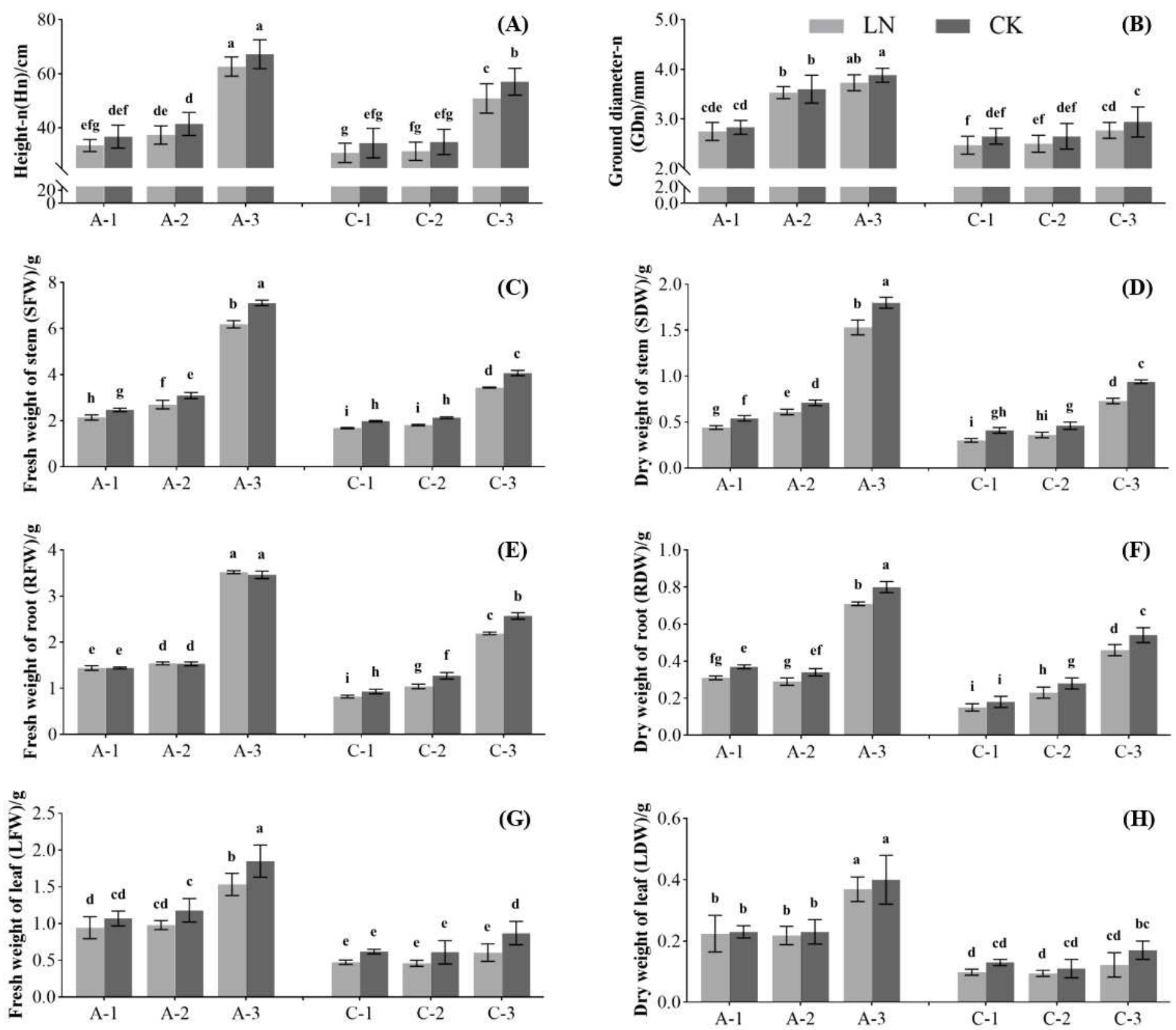

Figure 1

Effects of low $\mathrm{N}$ stress on growth traits of $\mathrm{N}$-efficient (A-1, A-2, and $\mathrm{A}-3$ ) and $\mathrm{N}$-inefficient ( $\mathrm{C}-1, \mathrm{C}-2$, and $\mathrm{C}$ -

$3)$ genotypes. Different letters above the column indicate significant differences between groups $(p<$ 0.05). (A) Height after treatment (Height-n, Hn); (B) Ground diameter after treatment (Ground diameter-n, GDn); (C) Fresh weight of the stem (SFW); (D) Dry weight of the stem (SDW); (E) Fresh weight of the root (RFW); (F) Dry weight of the root (RDW); (G) Fresh weight of the leaf (LFW); (H) Dry weight of the leaf (LDW). 

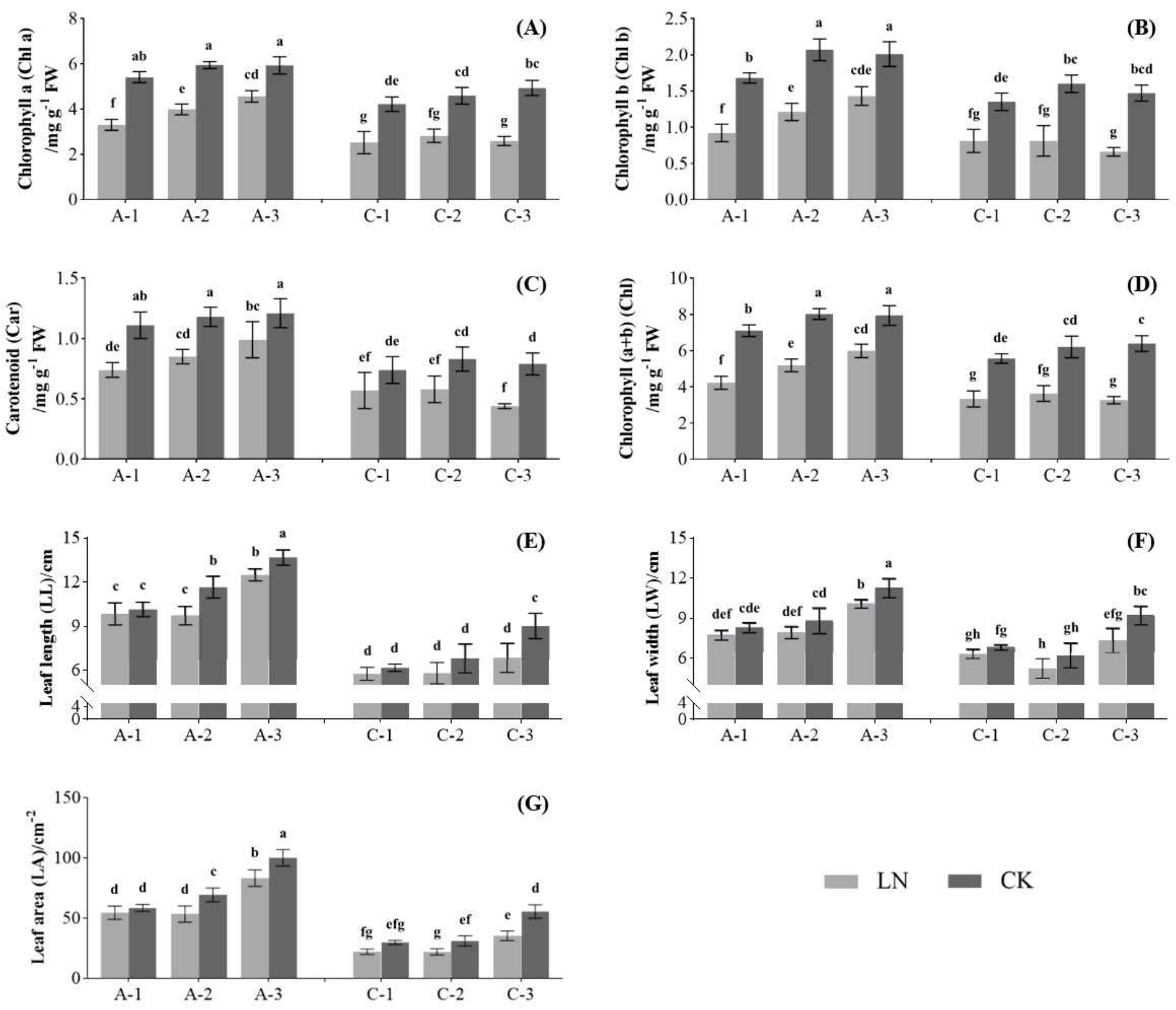

$\mathrm{LN}=\mathrm{CK}$

Figure 2

Effects of low $\mathrm{N}$ stress on leaf morphology and chlorophyll content of $\mathrm{N}$-efficient (A-1, A-2 and A-3) and Ninefficient ( $C-1, C-2$ and $C-3)$ genotypes. Different letters above the column indicate significant differences between the groups $(p<0.05)$. (A) Chlorophyll a (Chl a); (B) Chlorophyll b (Chl b); (C) Carotenoid (Car); (D) Chlorophyll $(a+b)(C h l) ;(E)$ Leaf length (LL); $(F)$ Leaf width (LW); (G) Leaf area (LA). 

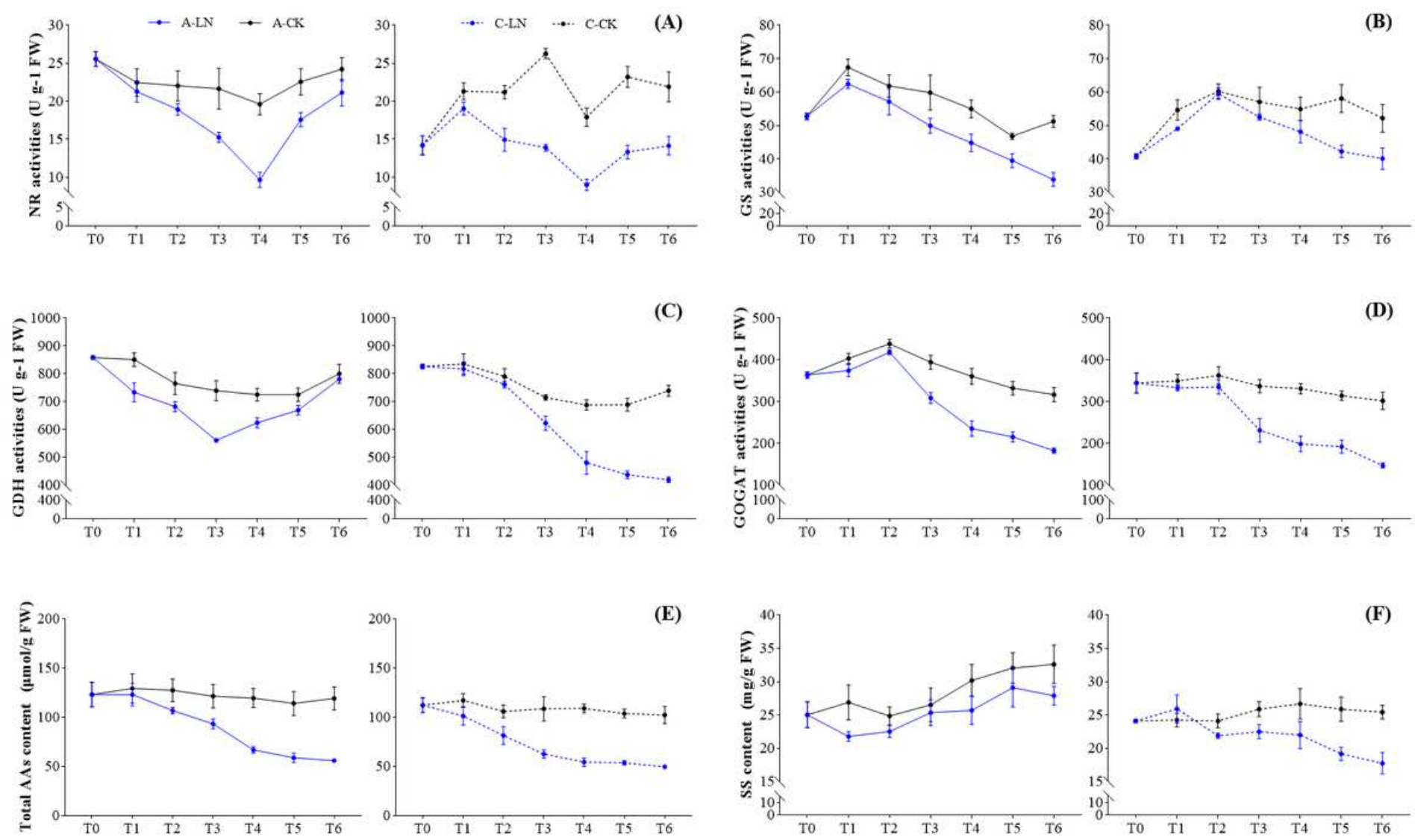

\section{Figure 3}

The change trends of enzyme activities, total amino acid contents, and soluble sugar contents in leaves during $\mathrm{N}$ treatment of $\mathrm{N}$-efficient $(\mathrm{A})$ and $\mathrm{N}$-inefficient (C) genotypes. T0, T1, T2, T3, T4, T5, and T6 represent $0,3,5,10,20,30$, and 40 days of $N$ treatment, respectively. (A) Nitrate reductase activities (NR); (B) Glutamine synthetase activities (GS); (C) Glutamate dehydrogenase activities (GDH); (D) Glutamic acid synthetase activities (GOGAT); (E) Total amino acid contents (AAs); (F) Soluble sugar contents (SSs).
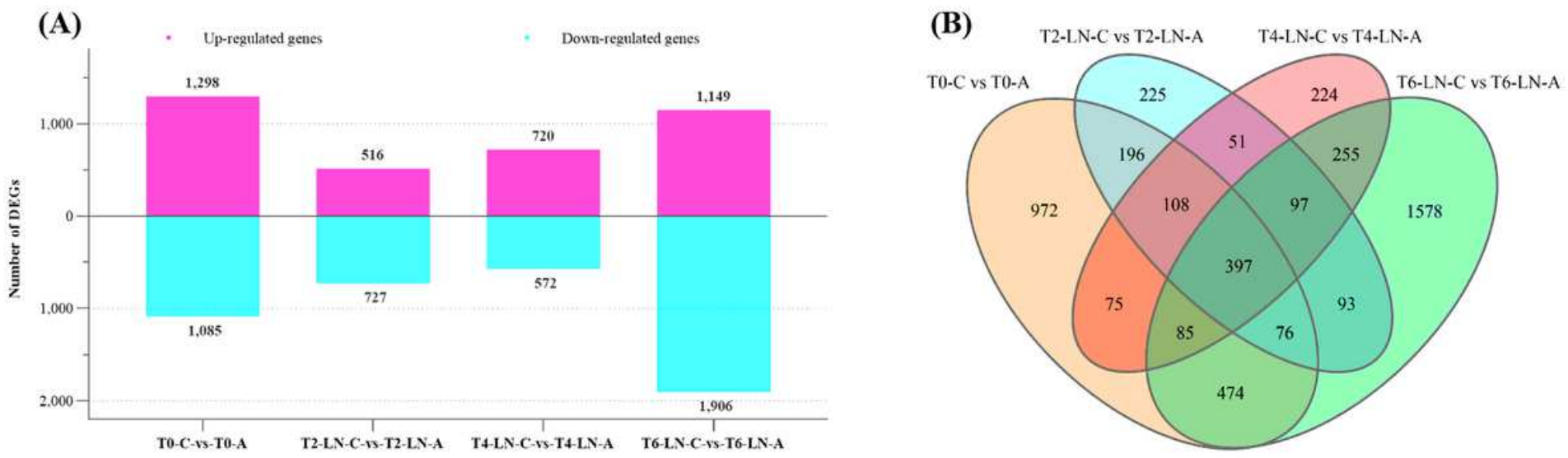

Figure 4 
(A) Bar chart showing numbers of upregulated and downregulated differentially expressed genes (DEGs) in the four comparison groups (TO-C vs. T0-A, T2-LN-C vs. T2-LN-A, T4-LN-C vs. T4-LN-A and T6-LN-C vs. T6-LN-A). The magenta column shows upregulated DEGs, and the cyan column shows downregulated DEGs. LN: low nitrogen treatment. (B) Venn diagram showing that the distribution of DEGs identified in the comparison of genotypes $\mathrm{A}$ and $\mathrm{C}$ are common and specific to T0, T2, T4, and T6.

\begin{tabular}{|c|c|c|c|c|c|c|}
\hline 0.000 & 0.889 & 0.211 & 0.000 & 0.733 & \multirow{5}{*}{\multicolumn{2}{|c|}{\begin{tabular}{l|l} 
Biosynthesis of secondary metabolites & Pathways \\
Glutathione metabolism & Environmental Information Processing \\
Starch and sucrose metabolism & Genetic Information Processing \\
Phenylalanine metabolism & Metabolism \\
Flavonoid biosvnthesis &
\end{tabular}}} \\
\hline 0.001 & 0.543 & 0.221 & 0.039 & 0.739 & & \\
\hline 0.001 & 0.717 & 0.764 & 0.044 & & & \\
\hline 0.004 & & 0.420 & 0.042 & 0.047 & & \\
\hline 0.008 & 0.002 & & 0.285 & 0.012 & & \\
\hline 0.041 & 0.212 & & & & Thiamine metabolism & \\
\hline 0.054 & 0.006 & & 0.041 & 0.026 & Stilbenoid, diarylheptanoid and gingerol bio & \\
\hline 0.067 & 0.944 & 0.441 & 0.001 & 0.203 & Metabolic pathways & \\
\hline 0.071 & 0.586 & 0.386 & 0.001 & 0.241 & Phenylpropanoid biosynthesis & \\
\hline 0.116 & & 0.417 & 0.014 & & Tyrosine metabolism & $p$ value \\
\hline 0.302 & & & 0.155 & 0.046 & Brassinosteroid biosynthesis & 0.95 \\
\hline 0.503 & 0.037 & & 0.344 & & Ascorbate and aldarate metabolism & \\
\hline 0.576 & & & 0.011 & & Fatty acid metabolism & 0.75 \\
\hline 0.794 & 0.258 & & 0.017 & 0.819 & Pentose and glucuronate interconversions & \\
\hline 0.895 & & 0.092 & 0.999 & 0.000 & Photosynthesis & \\
\hline 0.996 & & 0.203 & 1.000 & 0.000 & Oxidative phosphorylation & 0.5 \\
\hline & & & 0.001 & & Indole alkaloid biosynthesis & \\
\hline 0.225 & & & 0.354 & 0.040 & DNA replication & \\
\hline 0.663 & 0.338 & & 0.773 & 0.005 & Homologous recombination & 0.25 \\
\hline 0.283 & 0.044 & & 0.196 & 0.441 & ABC transporters & \\
\hline 0.452 & 0.322 & 0.042 & 0.263 & 0.867 & MAPK signaling pathway-plant & 0.05 \\
\hline 0.892 & 0.055 & 0.913 & 0.000 & & Plant hormone signal transduction & 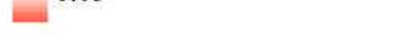 \\
\hline
\end{tabular}

\section{Figure 5}

Results of the Kyoto Encyclopedia of Genes and Genomes (KEGG) pathway enrichment analysis of the special and common differentially expressed genes (DEGs) between genotypes $A$ and $C$ at different time points during the response to low $\mathrm{N}$ stress. T0 special, T2 special, T4 special, and T6 special represent the specific DEGs at T0, T2, T4, and T6 between genotypes A and C, respectively. Common indicates the common DEGs at T0, T2, T4, and T6 between genotypes $A$ and $C$. 
(A)

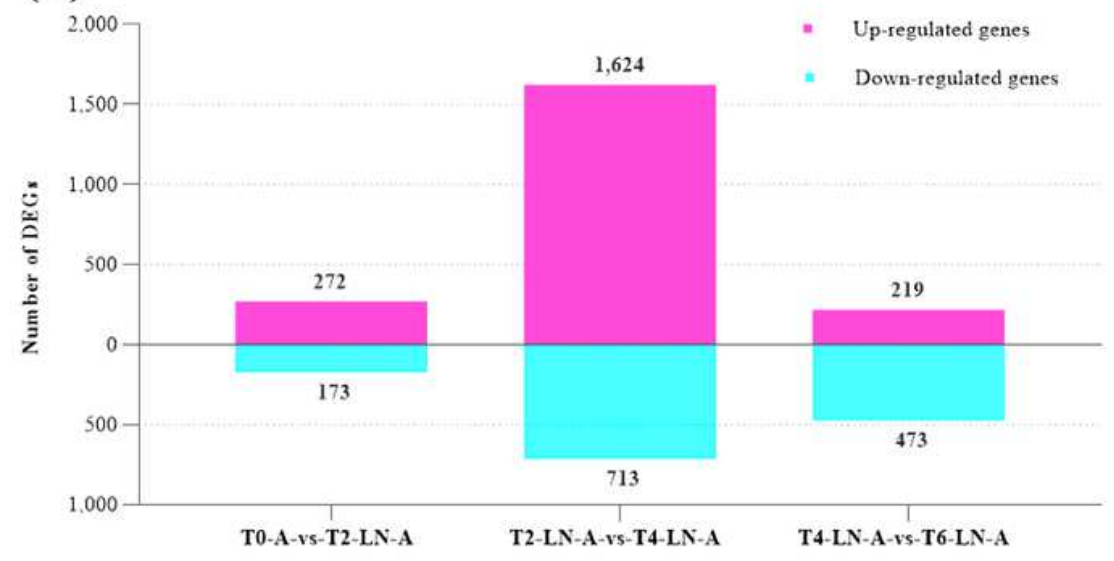

(B)

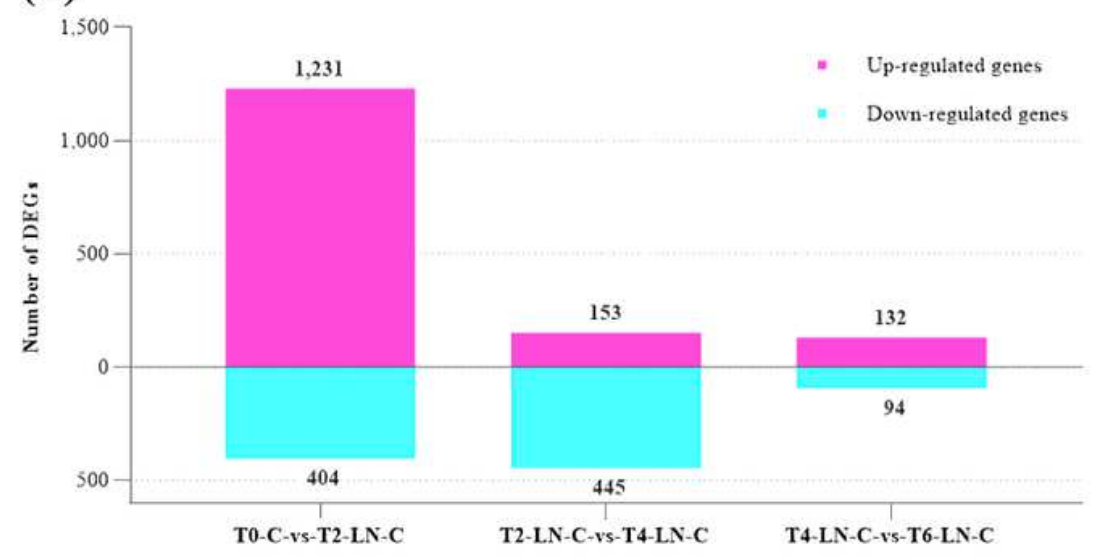

(C)
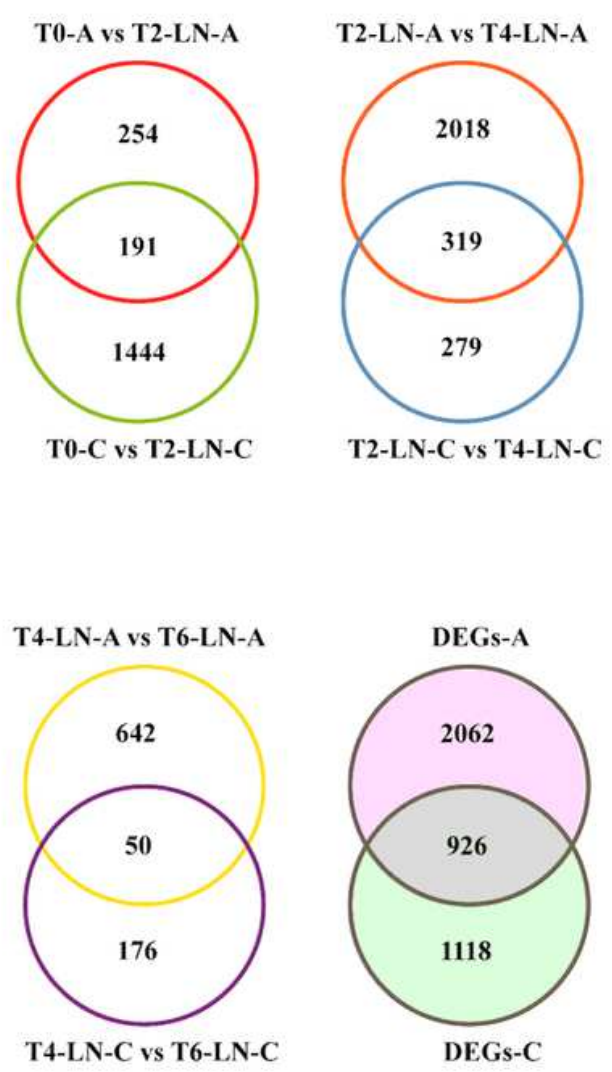

Figure 6

(A) and (B) bar charts show numbers of upregulated and downregulated differentially expressed genes (DEGs) in the three comparison groups of A (T0-A vs. T2-LN-A, T2-LN-A vs. T4-LN-A, and T4-LN-A vs. T6LN-A) and C (T0-C vs. T2-LN-C, T2-LN-C vs. T4-LN-C, and T4-LN-C vs. T6-LN-C) genotypes, respectively. The magenta column shows upregulated DEGs, and the cyan column shows downregulated DEGs. LN: low nitrogen treatment. (C) Venn diagrams showing that the distribution of DEGs identified in the comparison of different periods are common and specific to genotypes $A$ and $C$. DEGs-A and DEGs-C represent all the DEGs identified from genotypes $A$ and $C$ during low $N$ stress treatment, respectively. 


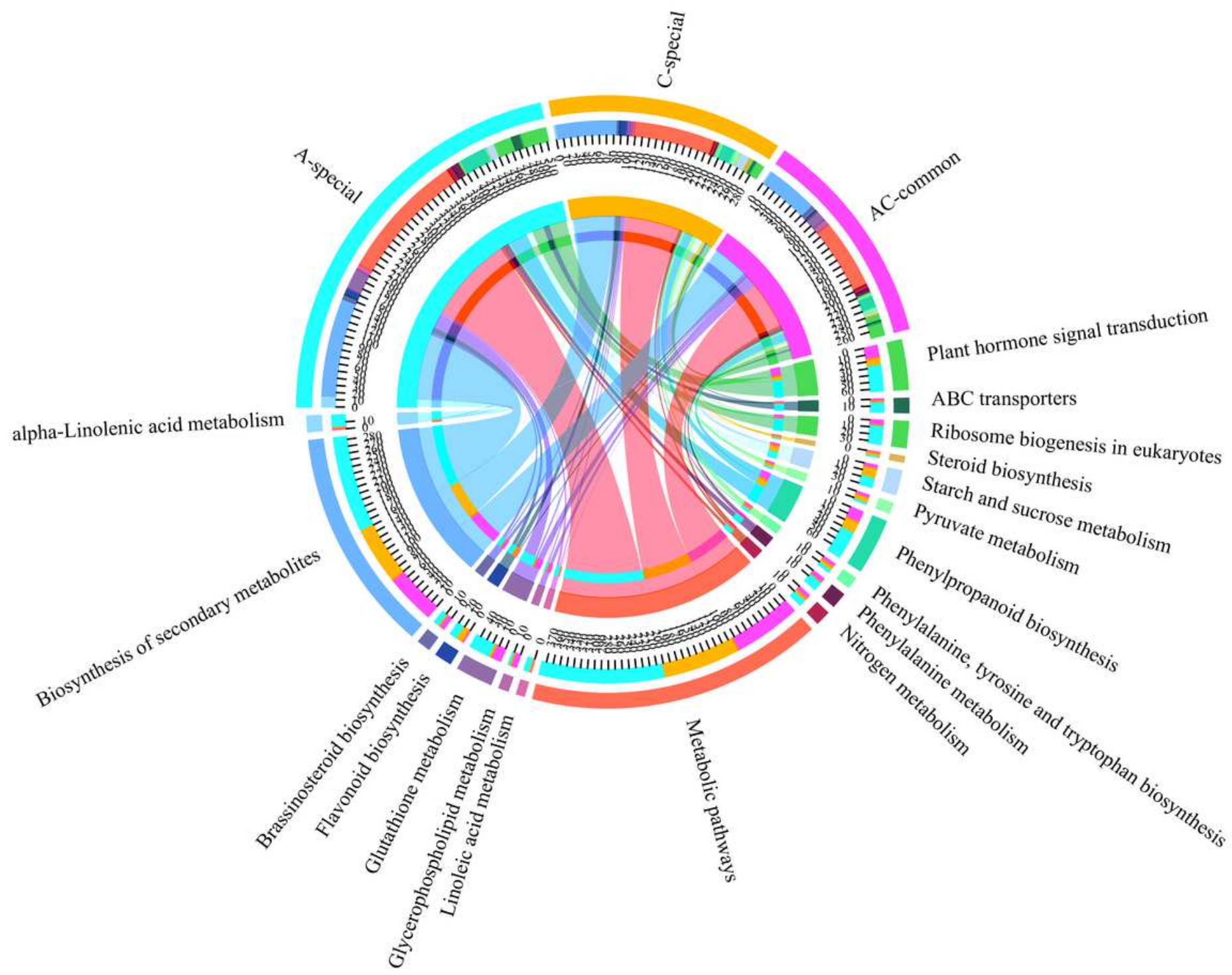

Figure 7

Results of the Kyoto Encyclopedia of Genes and Genomes (KEGG) pathway enrichment analysis of the special and common differentially expressed genes (DEGs) between genotypes $A$ and $C$ during the response to low $\mathrm{N}$ stress. A-special and C-special represent the specific DEGs in genotypes $A$ and $C$, respectively. AC-common indicates the common DEGs between genotypes $\mathrm{A}$ and $\mathrm{C}$. 
(A)
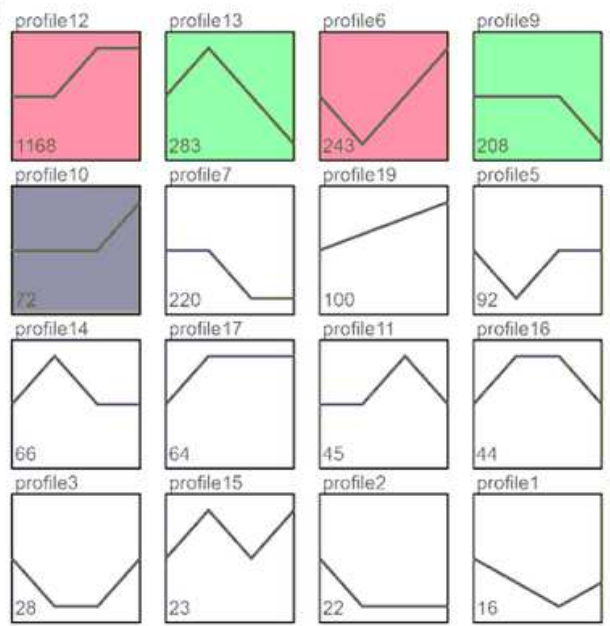

N-efficient genotypes (A)

(C)
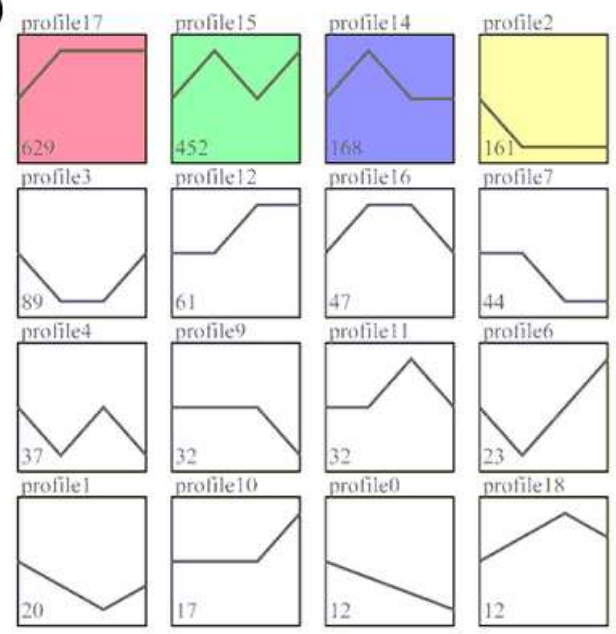

$\mathrm{N}$-inefficient genotypes (C)
(B)
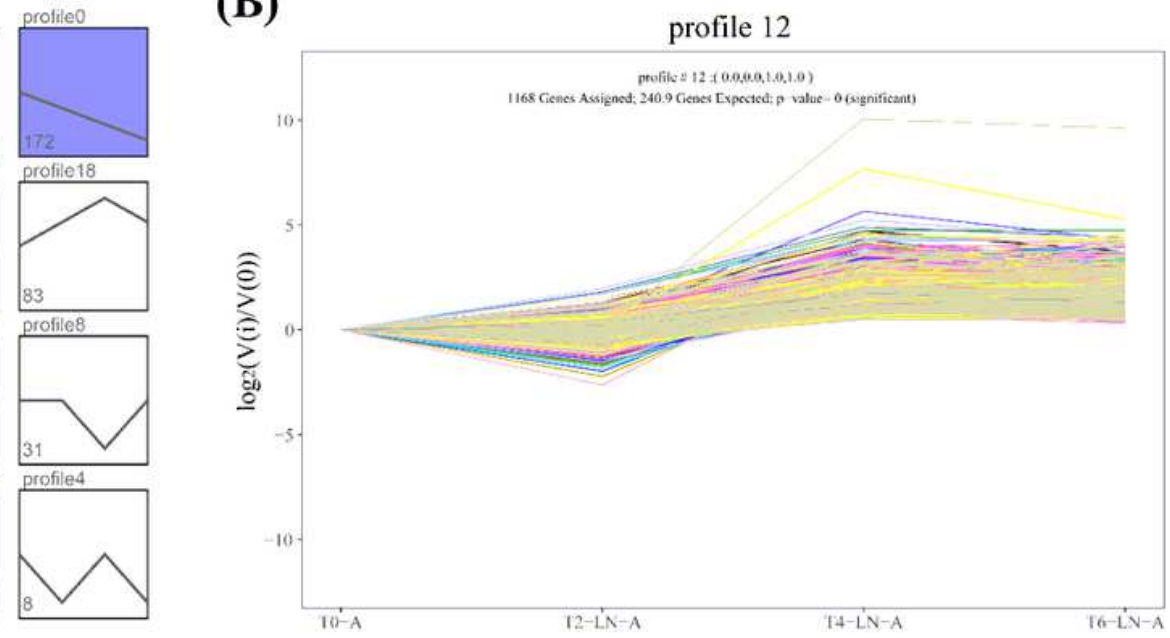

N-efficient genotypes (A)

(D)
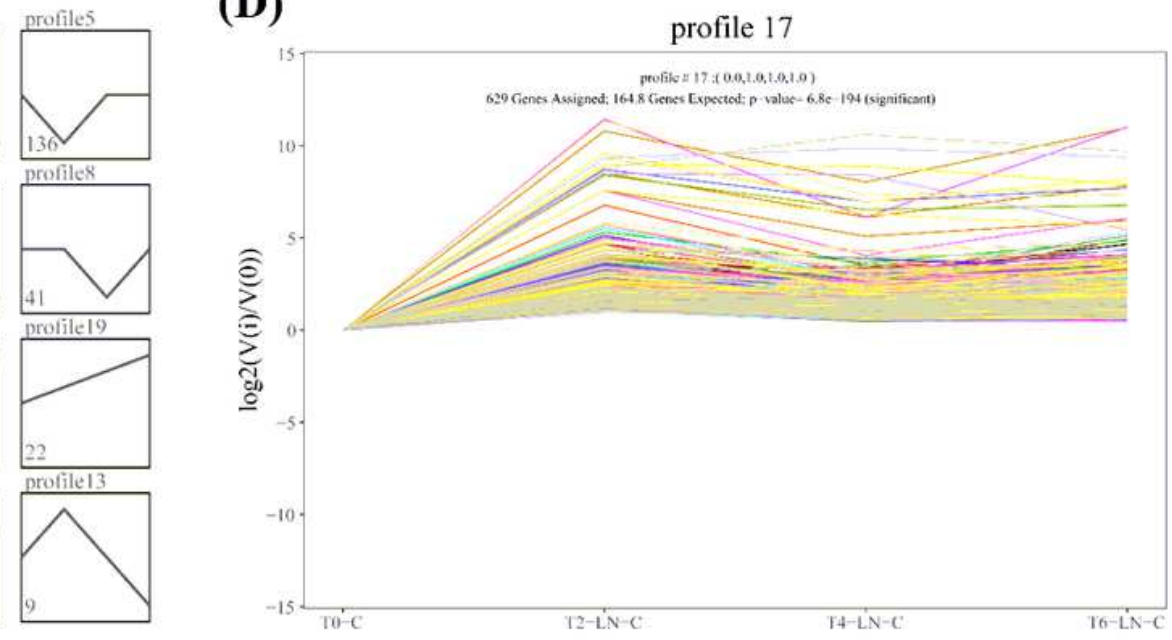

$\mathrm{N}$-inefficient genotypes $(\mathrm{C})$

\section{Figure 8}

Gene expression patterns across four-time points (T0, T2, T4, and T6) in genotypes $A$ and $C$ under low $N$ stress. $(A)$ and $(C)$ indicate the variation trend of differentially expressed genes (DEGs) in genotypes $A$ and $C$, respectively. Above the box is the ID of the changing trend, and the number in the box indicates the number of DEGs contained in the trend. The grid with color indicates a significantly enrichment trend ( $p<$ $0.05)$, and the closer the color is, the more similar the changing trend is. (B) and (D) represent the changing trend of genes in profile 12 with genotype $A$ and profile 17 with genotype $C$, respectively. 


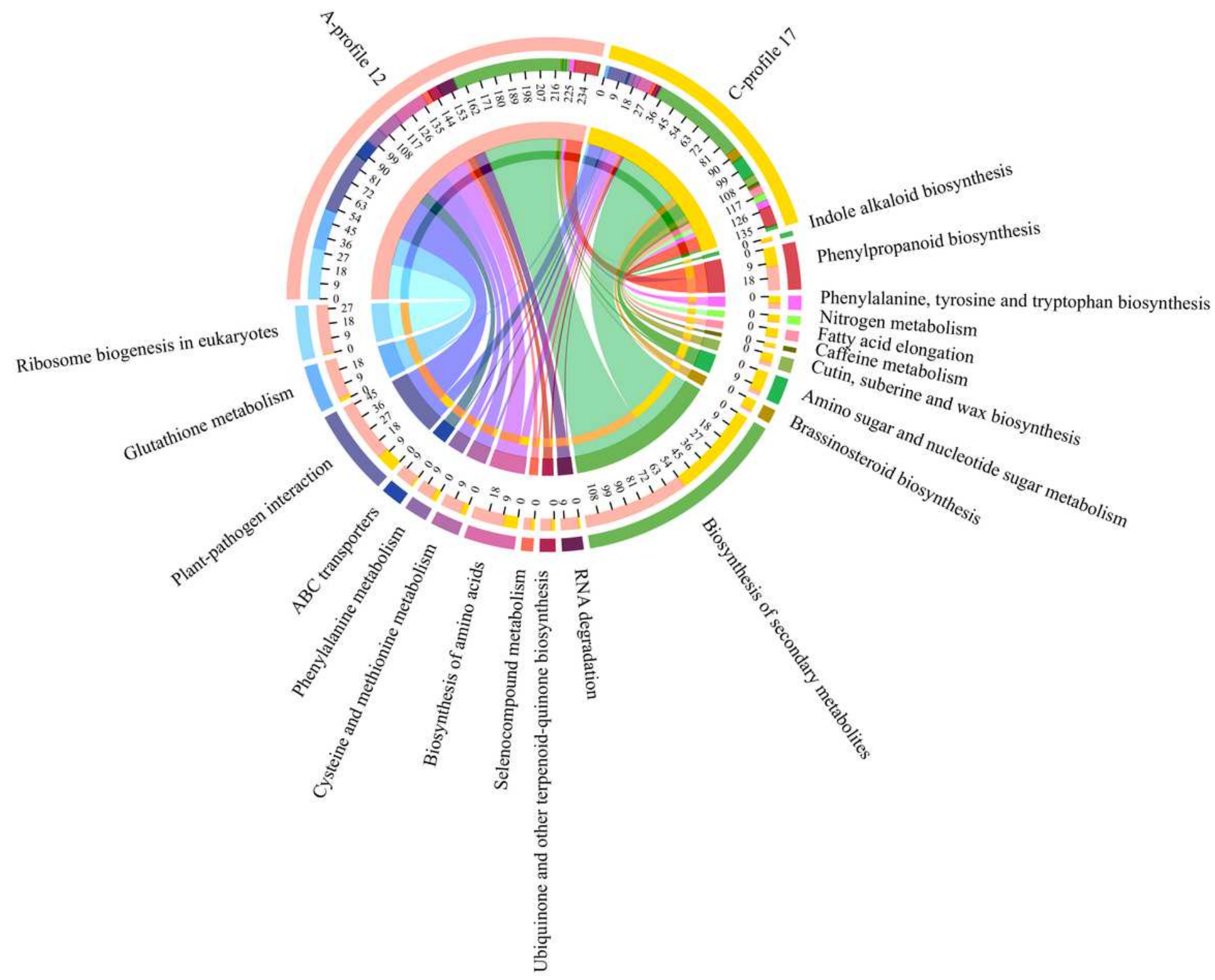

\section{Figure 9}

Results of the Kyoto Encyclopedia of Genes and Genomes (KEGG) pathway enrichment analysis of differentially expressed genes (DEGs) in profile 12 of genotype A (A-profile 12) and profile 17 of genotype $C$ (C-profile 17). The 10 pathways on the left are the top-10 metabolic pathways with significantly enrichment in A-profile 12, and the 10 pathways on the right are the top 10 metabolic pathways with significantly enrichment in C-profile $17(p<0.05)$. 

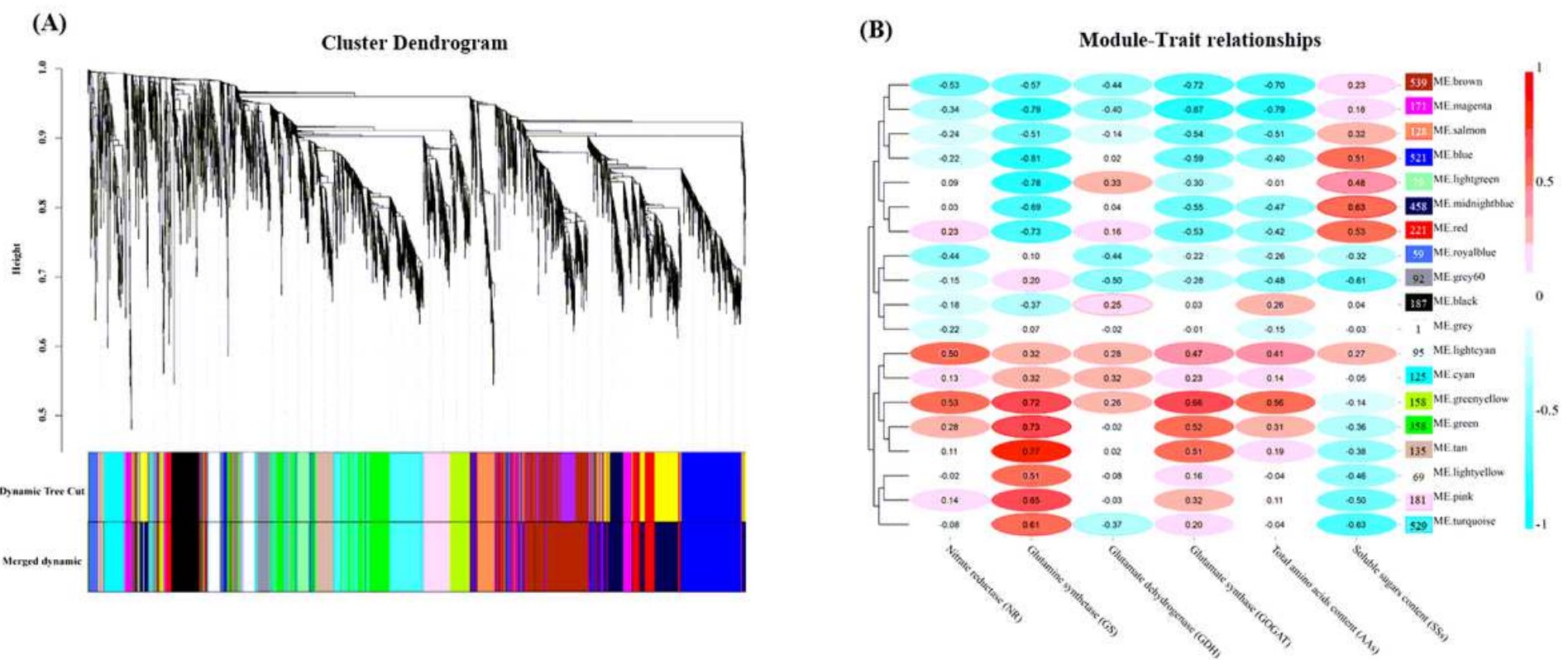

Figure 10

Weighted gene co-expression network analysis (WGCNA) of differentially expressed genes (DEGs) identified in the genotypes $A$ and $C$ over three-time stages under low N stress. (A) Gene cluster dendrogram and 19 gene module divisions of DEGs, in which a major tree branch represents a module, and different colors represent different modules. (B) Correlation heatmap between modules and traits. Each column presents the experimental traits. The number in the oval box represents the correlation coefficient, which ranges from $\otimes 1$ (cyan) to 1 (red). We set an absolute value of the correlation coefficient greater than 0.75 to indicate that there is a strong correlation between gene modules and traits. The number in the rectangular box on the right indicates the number of the genes contained in the corresponding gene module.

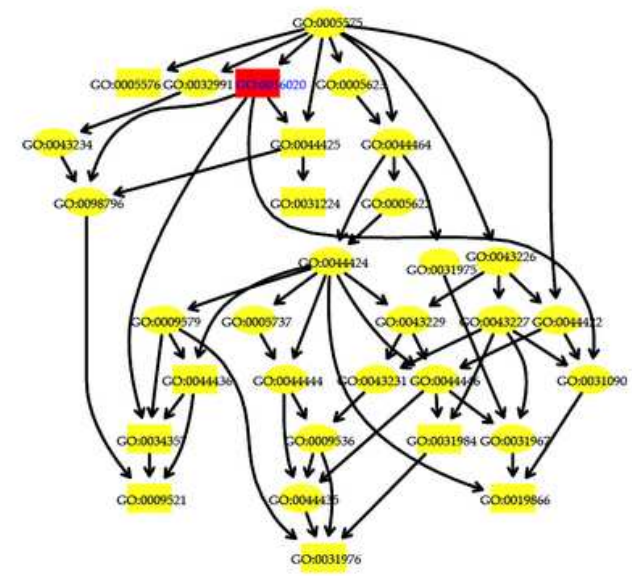

Cellular component

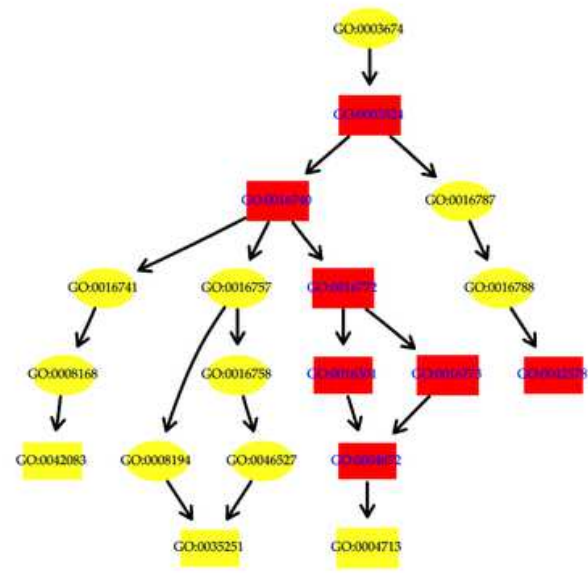

Molecular function

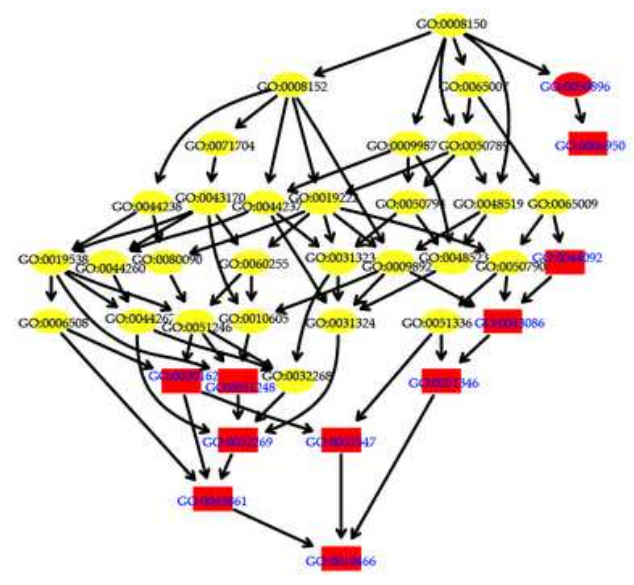

Biological process

Figure 11 
Results of the gene ontology (GO) functional enrichment analysis of genes in the 'magenta' module. Red filled GO items were significantly enriched $(p<0.05)$ and yellow ones were not significantly enriched $(p>$ 0.05). The rectangles in each network diagram represent the top $10 \mathrm{GO}$ terms with significance in cellular component, molecular function, and biological process, respectively.
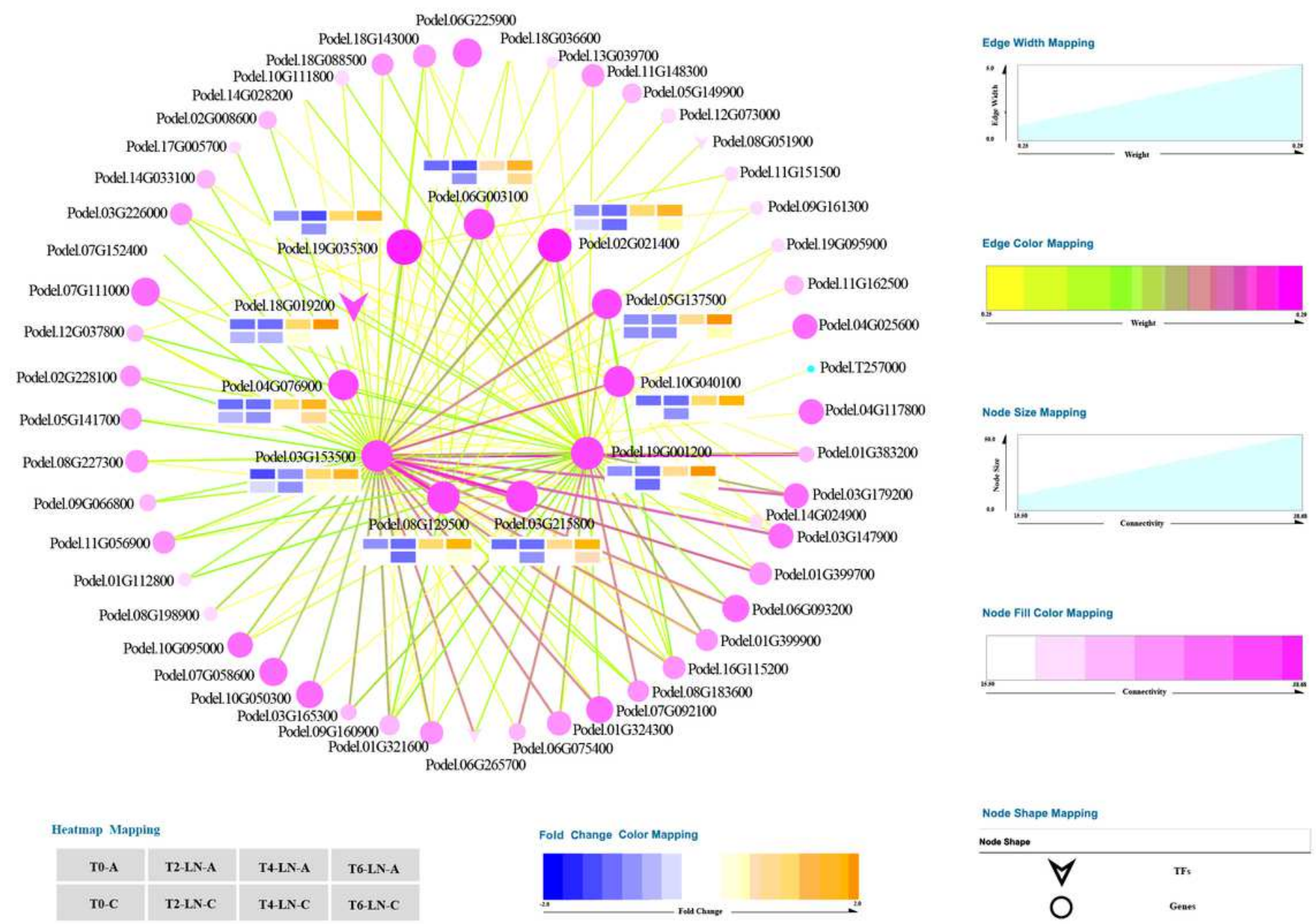

\section{Figure 12}

Cytoscape representation of the top 150 network relationships related to hub genes that were selected according to the weight value in the 'magenta' module. The color of the lines between genes from orange to green to pink indicates that the correlation (weight value) between genes is becoming stronger, and the thicker the lines, the stronger the correlation (weight value). The larger the node, the pinker the color, indicating the greater connectivity of the gene in the module, and TFs represent transcription factors. The heat map next to the central gene shows the expression level of the gene in different samples, and the color from blue to orange indicates that the expression level is increasing. In the upper row, the four samples from left to right are T0-A, T2-LN-A, T4-LN-A, and T6-LN-A, respectively, and in the next row are TO-C, T2-LN-C, T4-LN-C, and T6-LN-C, respectively.

\section{Supplementary Files}


This is a list of supplementary files associated with this preprint. Click to download.

- SupplementaryTables.xlsx

- SupplementaryFigures.docx 